WellBeing International

WBI Studies Repository

$9-2003$

\title{
Neuroanatomy of the Harbor Porpoise (Phocoena phocoena) From Magnetic Resonance Images
}

\author{
Lori Marino \\ Emory University \\ Keith Sudheimer \\ Michigan State University \\ Diana Sarko \\ Emory University \\ Gayle Sirpenski \\ Mystic Aquarium \& Institute for Exploration \\ John I. Johnson \\ Michigan State University
}

Follow this and additional works at: https://www.wellbeingintlstudiesrepository.org/acwp_vsm

\section{Recommended Citation}

Marino, L., Sudheimer, K., Sarko, D., Sirpenski, G., \& Johnson, J. I. (2003). Neuroanatomy of the harbor porpoise (Phocoena phocoena) from magnetic resonance images. Journal of morphology, 257(3), 308-347.

This material is brought to you for free and open access by WellBeing International. It has been accepted for inclusion by an authorized administrator of the WBI Studies Repository. For more information, please contact wbisr-info@wellbeingintl.org.

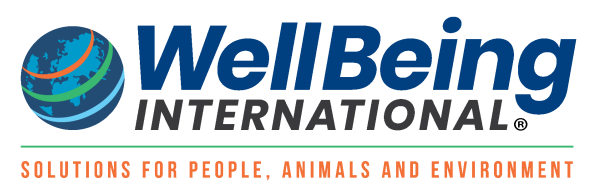




\title{
Neuroanatomy of the Harbor Porpoise (Phocoena phocoena) From Magnetic Resonance Images
}

\author{
Lori Marino, ${ }^{1}$ Keith Sudheimer, ${ }^{2}$ Diana Sarko, ${ }^{1}$ Gayle Sirpenski, ${ }^{3}$ and John I. Johnson ${ }^{2,3}$ \\ ${ }^{1}$ Emory University \\ ${ }^{2}$ Michigan State University \\ ${ }^{3}$ Mystic Aquarium \& Institute for Exploration
}

\section{KEYWORDS}

Porpoise, Phocoena phocoena, neuroanatomy, brain, magnetic resonance imaging, MRI

\begin{abstract}
Cetacean (dolphin, whale, and porpoise) brains are among the least-studied mammalian brains because of the formidability of collecting and histologically preparing such relatively rare and large specimens. Among cetaceans, there exist relatively few studies of the brain of the harbor porpoise (Phocoena phocoena). Magnetic resonance imaging (MRI) offers a means of observing the internal structure of the brain when traditional histological procedures are not practical. Therefore, MRI has become a critical tool in the study of the brain of cetaceans and other large species. This article represents the first MRI-based anatomically labeled threedimensional description of the harbor porpoise brain. Coronal plane sections of the brain of a young harbor porpoise were originally acquired and used to produce virtual digital scans in the other two orthogonal spatial planes. A sequential set of images in all three planes has been anatomically labeled and displays the proportions and positions of major neuroanatomical features. These images allow for the visualizing of the distinctive features of the harbor porpoise brain from various orientations by preserving the gross morphological structure of the specimen.
\end{abstract}

Cetaceans (dolphins, whales, and porpoises) are a highly modified group of mammals that are closely tied to artiodactyls, the "even-toed" ungulates. Recent morphological evidence supports the view that early whales diverged from an artiodactyl terrestrial ancestor _55-60 million years ago (Gingerich et al., 2001; Thewissen et al., 2001). Some of the most significant evolutionary changes that occurred among cetaceans were in brain morphology and relative size (Glezer et al., 1988). Modern cetacean brains represent an unusual blend of early mammalian characteristics and uniquely derived features Ridgway, 1986; Glezer et al., 1988; Manger et al., 1998). This constellation of neuroanatomical features displayed by cetaceans has been the focus of considerable interest within the field of comparative mammalian brain evolution (Glezer et al., 1988; Manger et al., 1998). 
Fig. 1. a-l: Phocoena phocoena. Posterior-to-anterior sequence of originally acquired 2.0-mm-thick coronal MR brain sections at8-mm intervals (a-e), 4-mm intervals (e-h), and 8-mm intervals (h-l), a labeled schematic illustration of each section, computer-generated images showing the level at which the section was taken in three orthogonal planes, and a computer-generated 3D reconstruction of the whole brain showing the brain digitally "cut" at the level of the section.
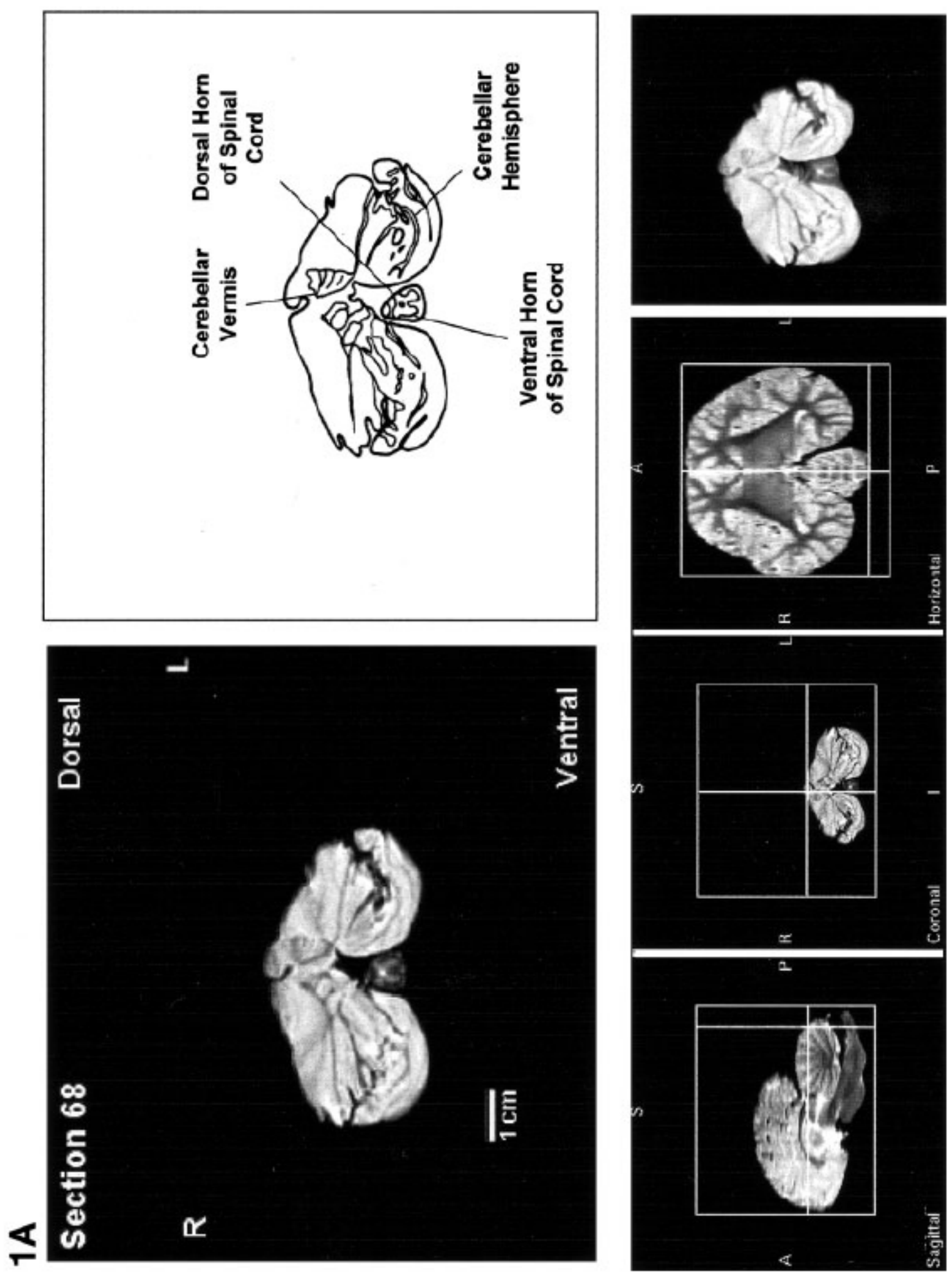
Figure 1. (continued)
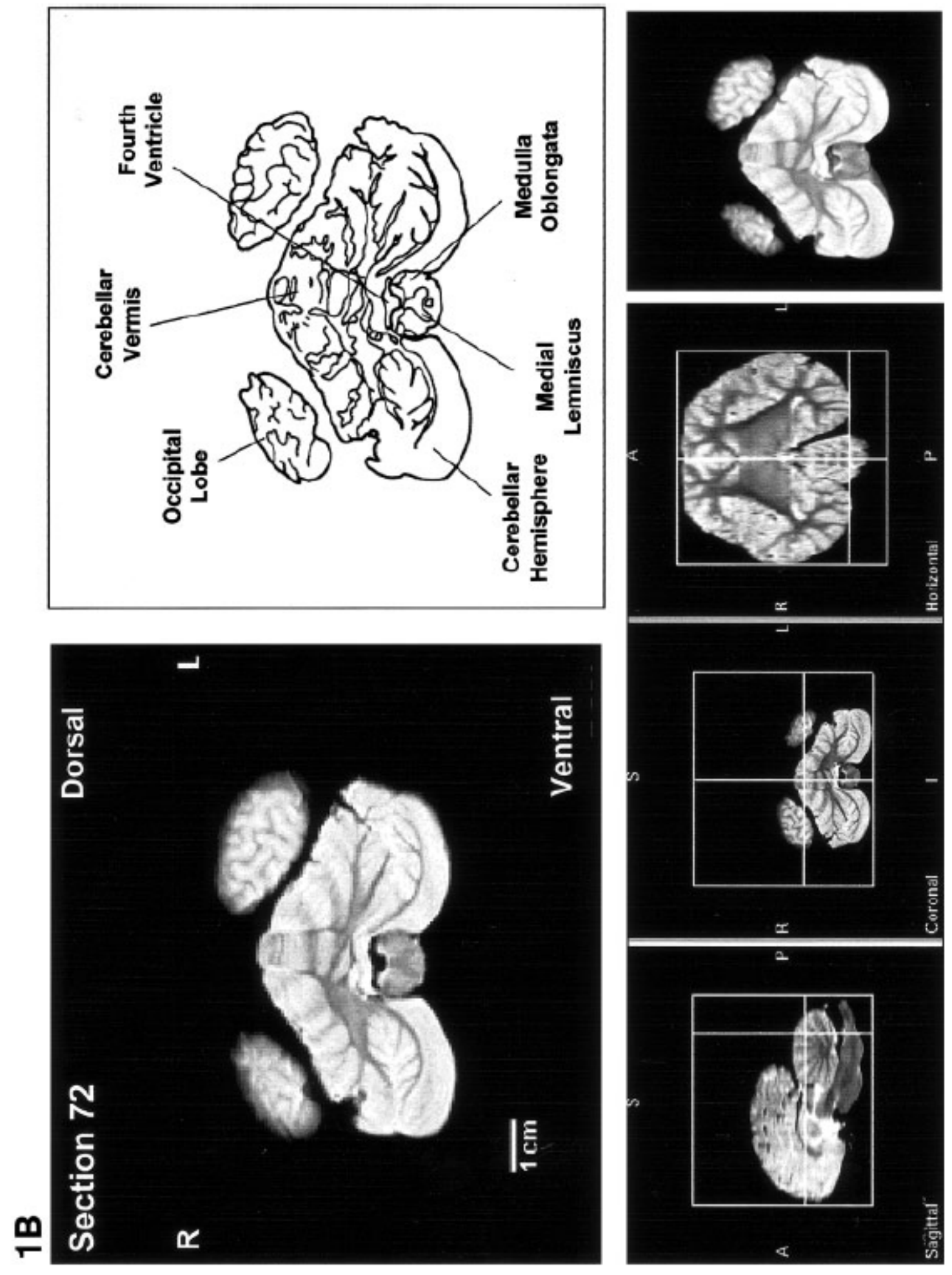
Figure 1. (continued)
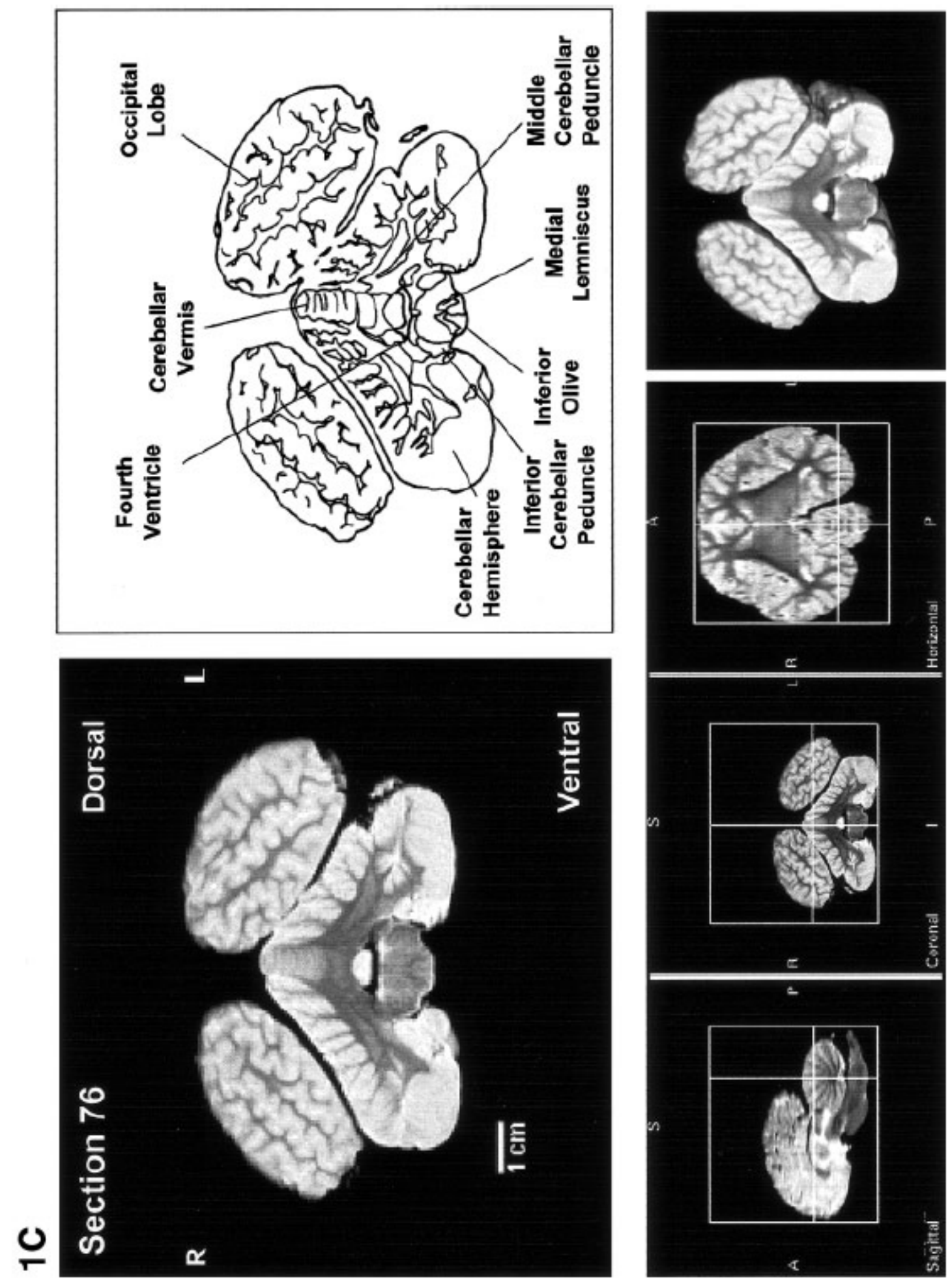
Figure 1. (continued)
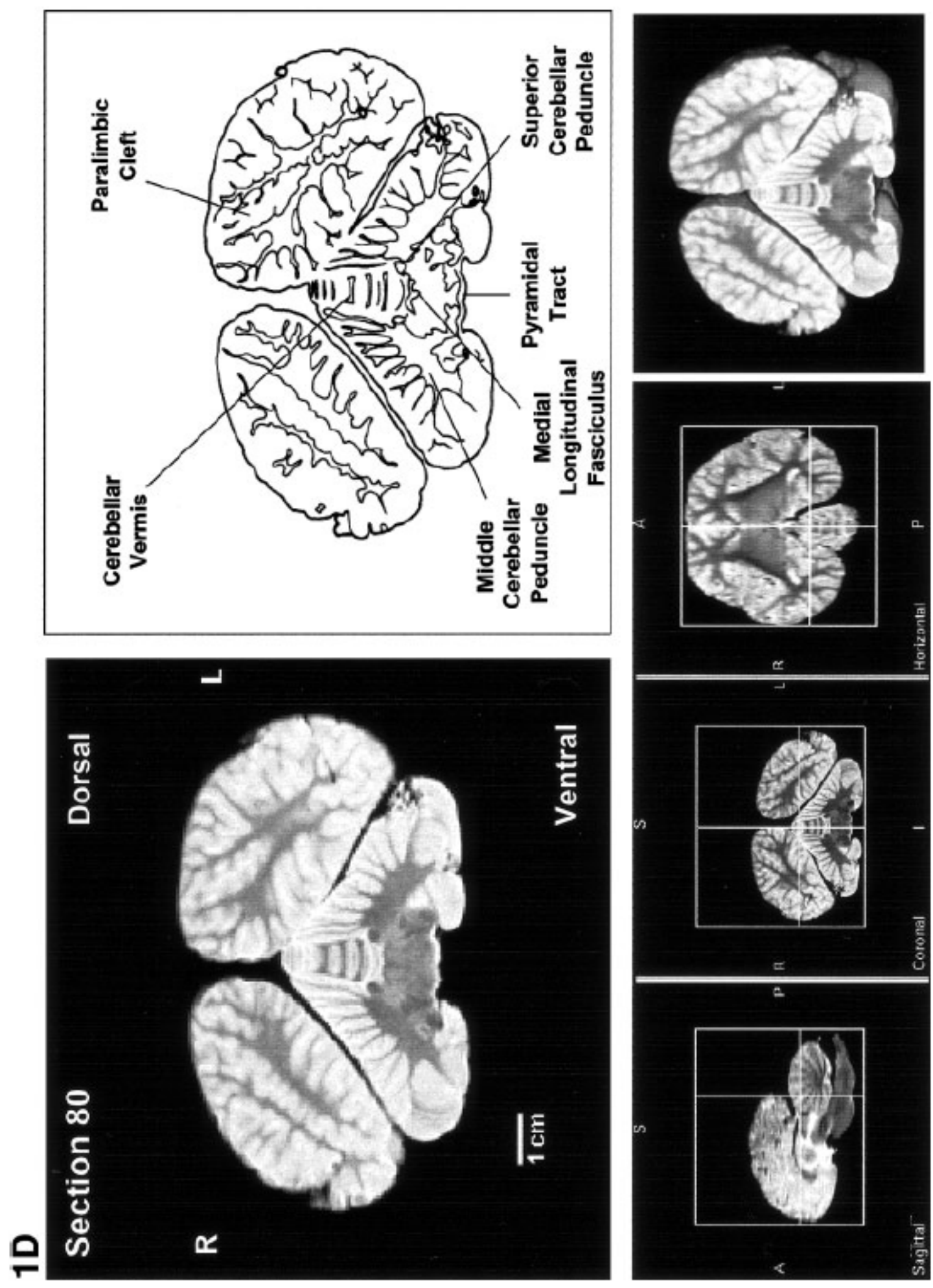
Figure 1. (continued)
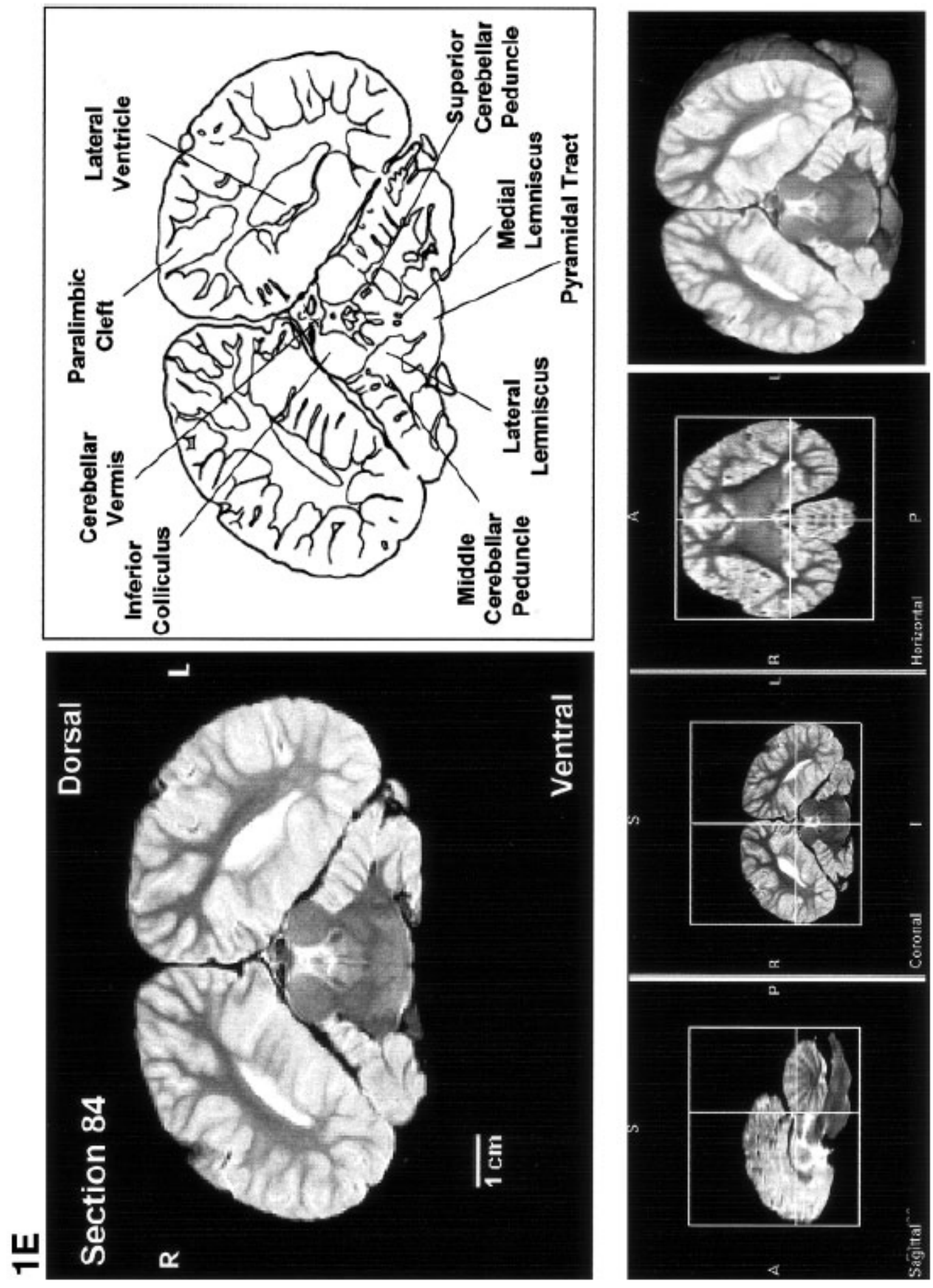
Figure 1. (continued)
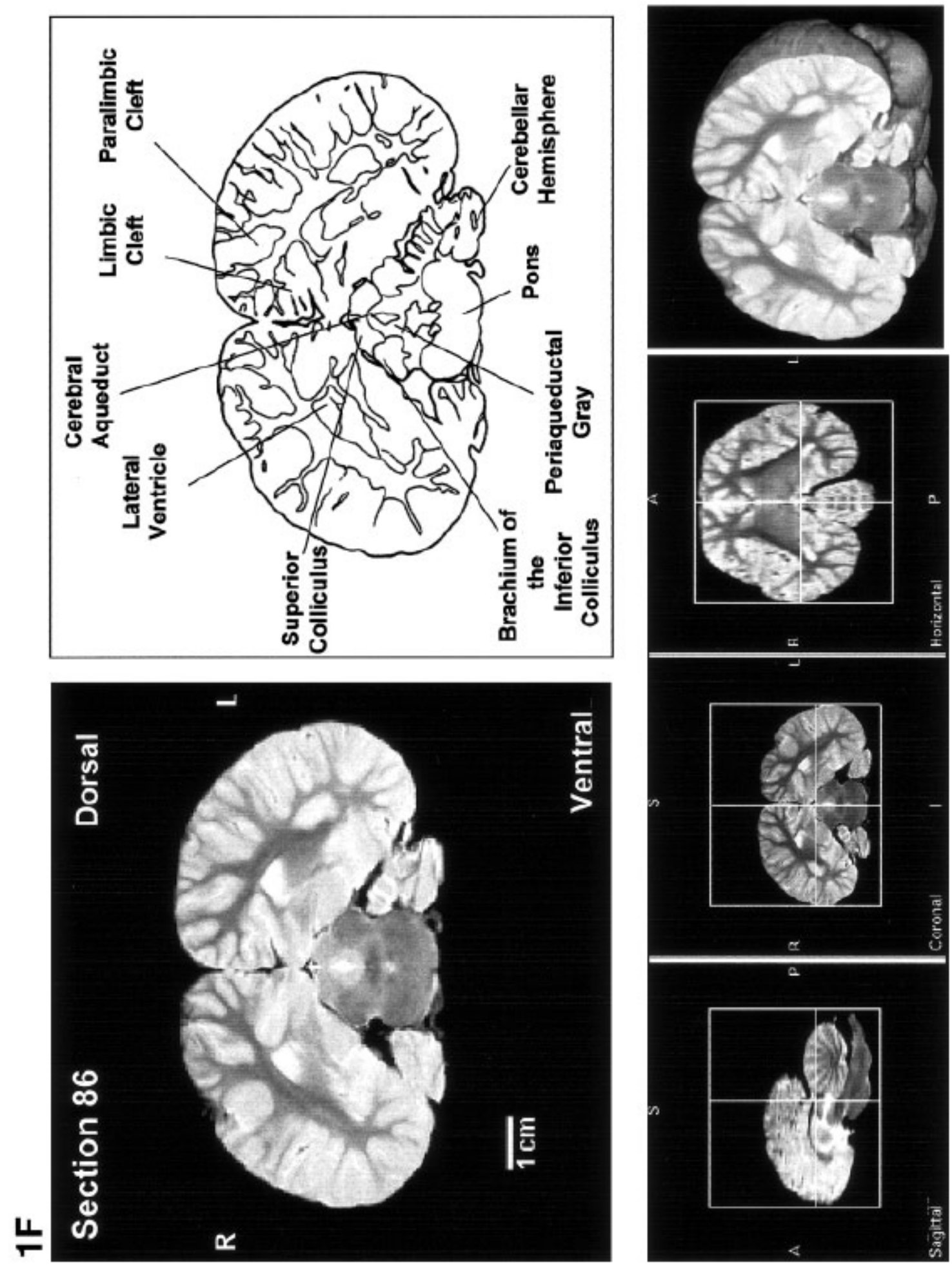
Figure 1. (continued)
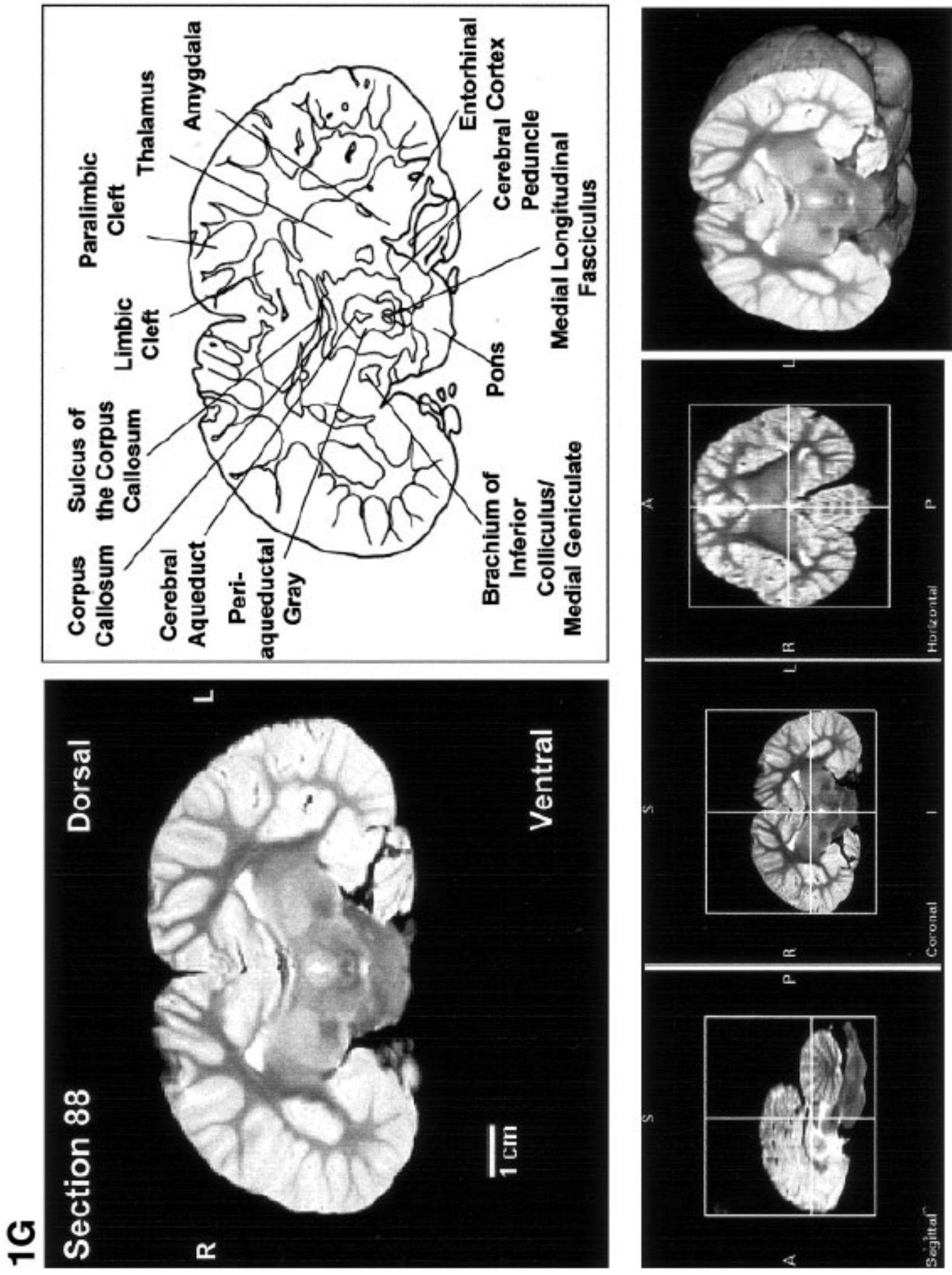
Figure 1. (continued)
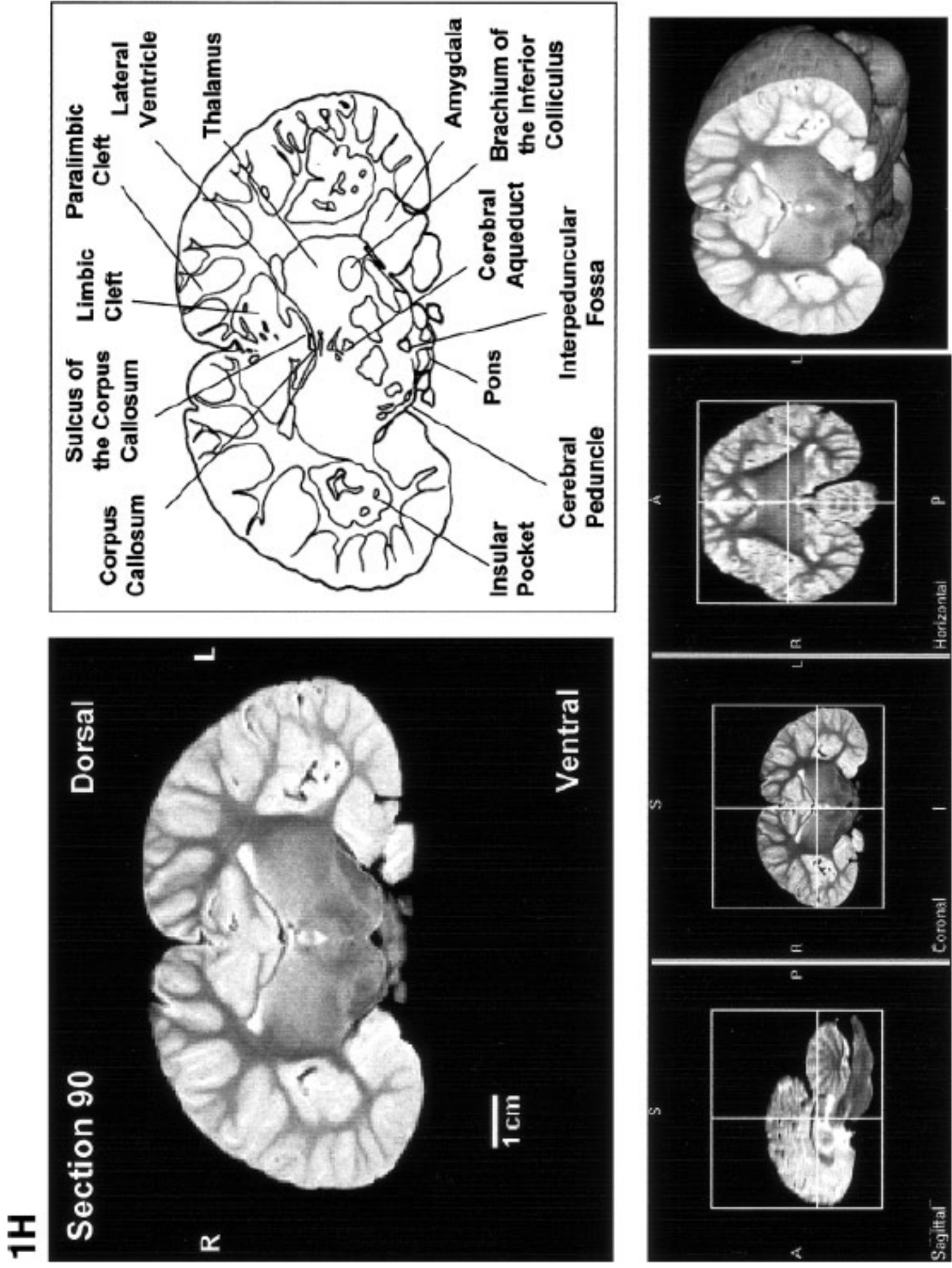
Figure 1. (continued)
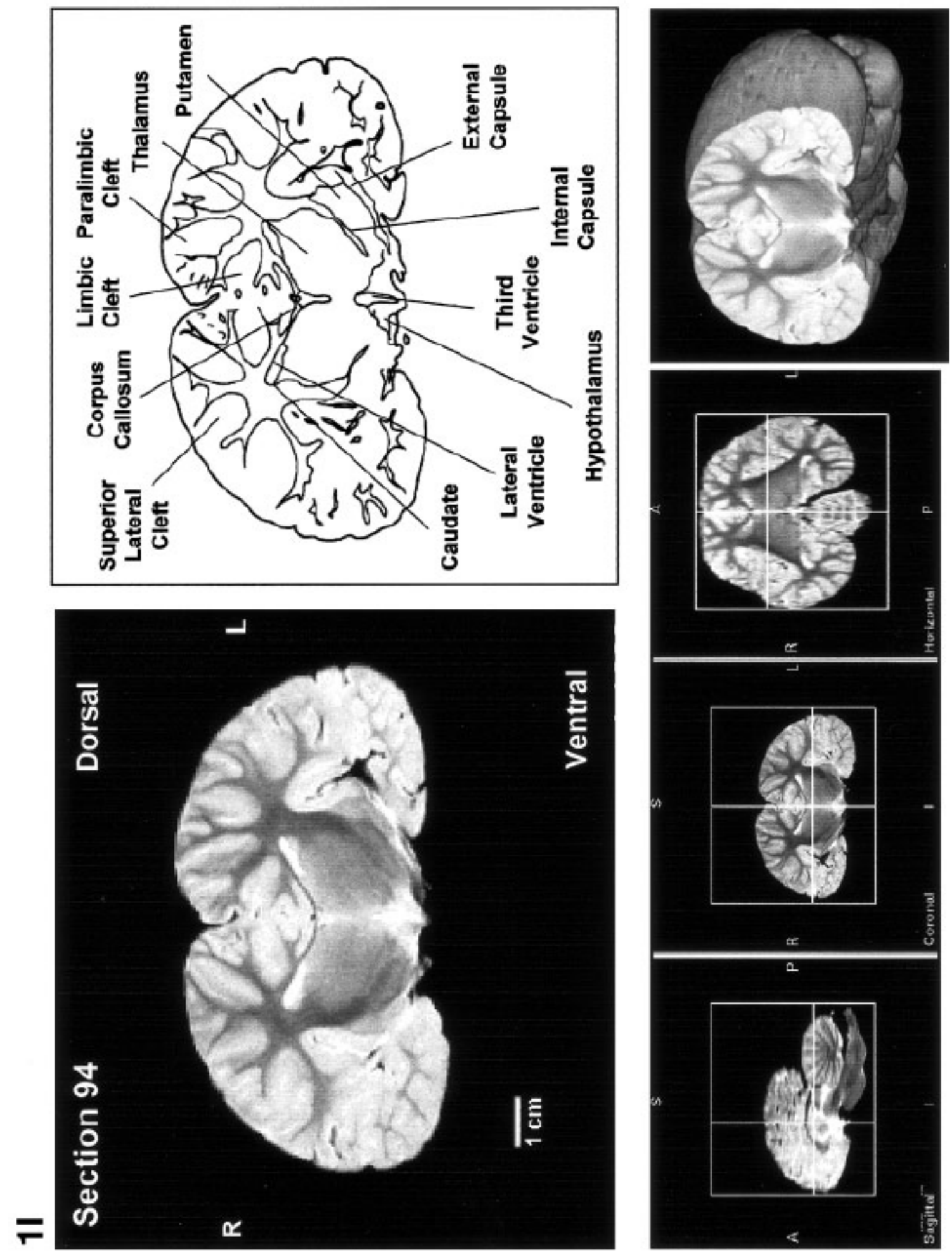
Figure 1. (continued)
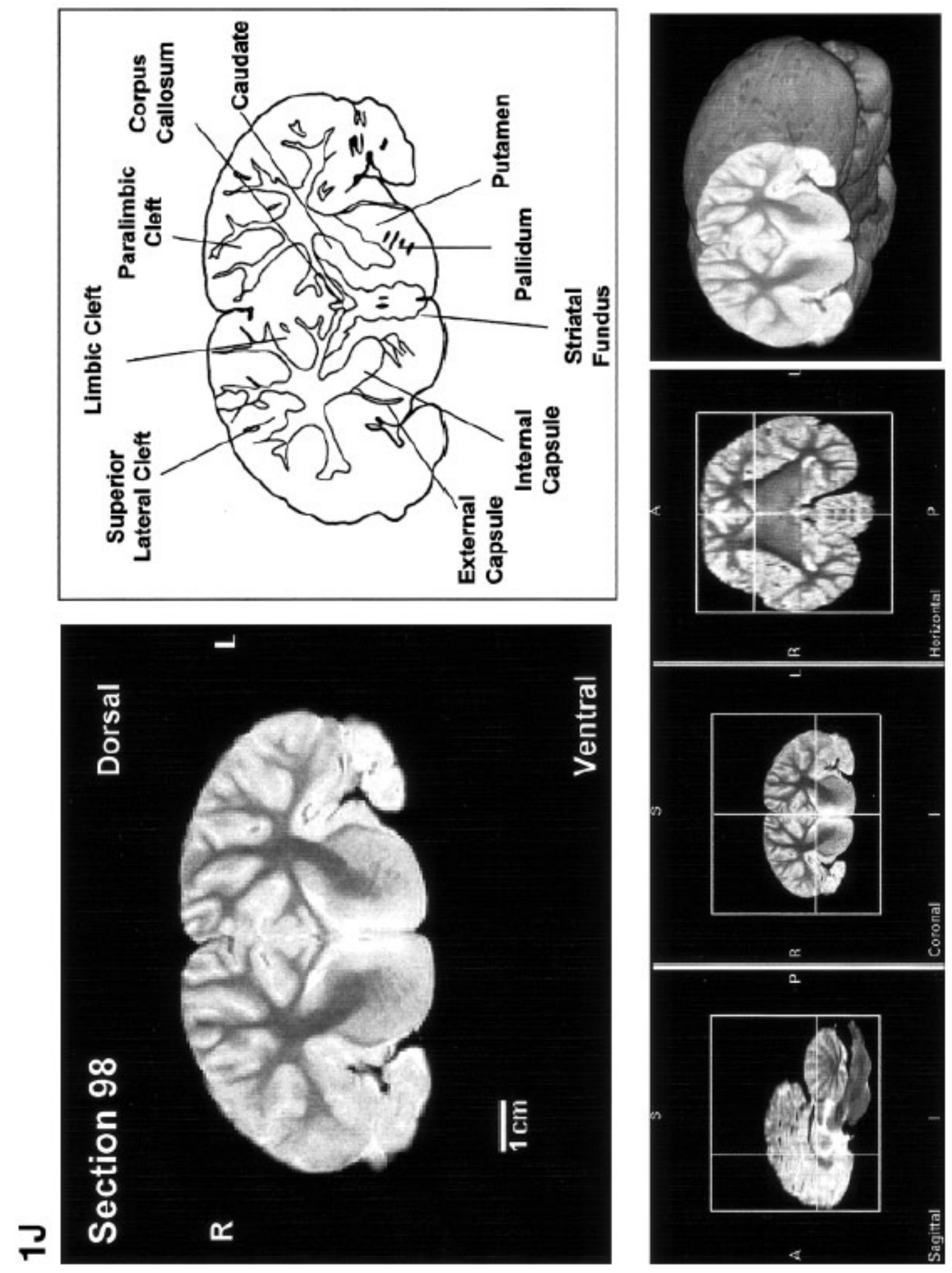
Figure 1. (continued)
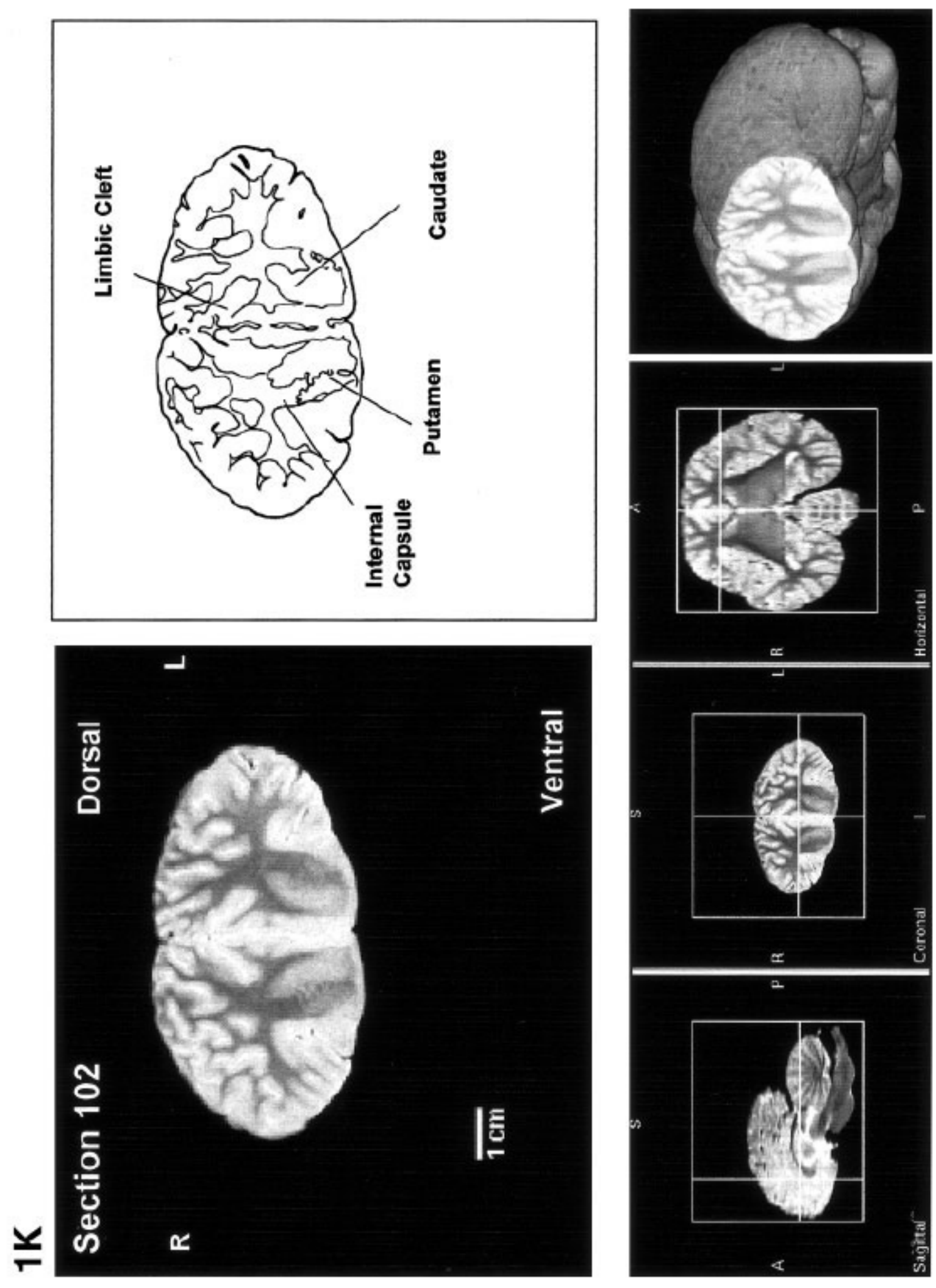
Figure 1. (continued)
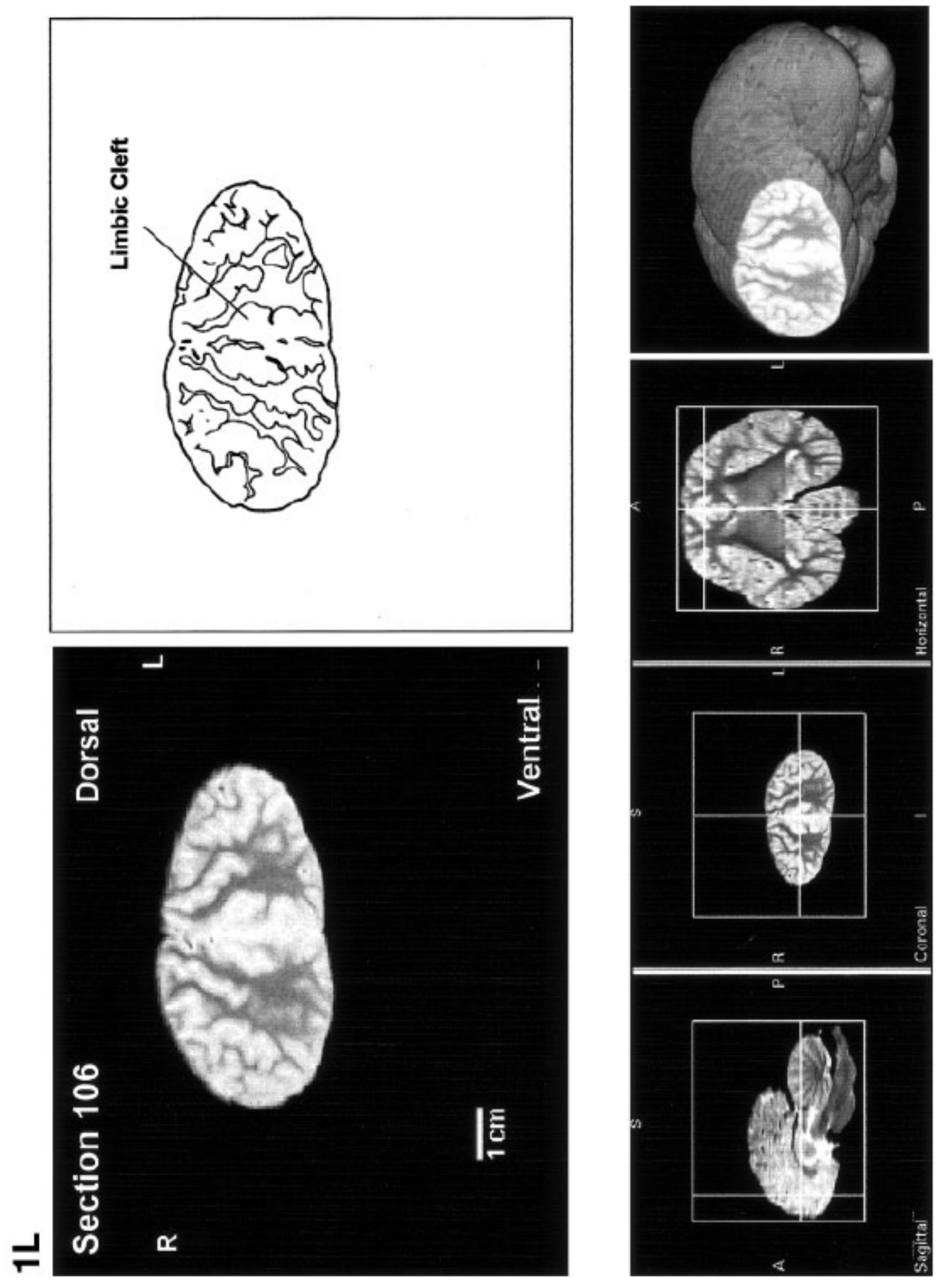

a.

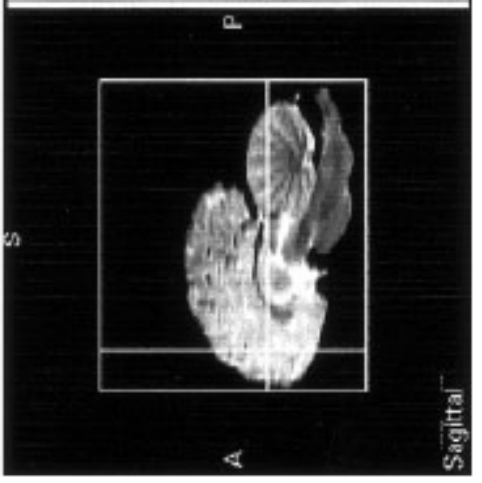


Fig. 2. a-I: Phocoena phocoena. Ventral-to-dorsal sequence of reconstructed "virtual" 0.6-mm thick horizontal sections at 4.2-mm intervals, a labeled schematic illustration of each section, computer-generated images showing the level at which the section was taken in three orthogonal planes, and a computer-generated three-dimensional reconstruction of the whole brain showing the brain digitally "cut" at the level of the section.
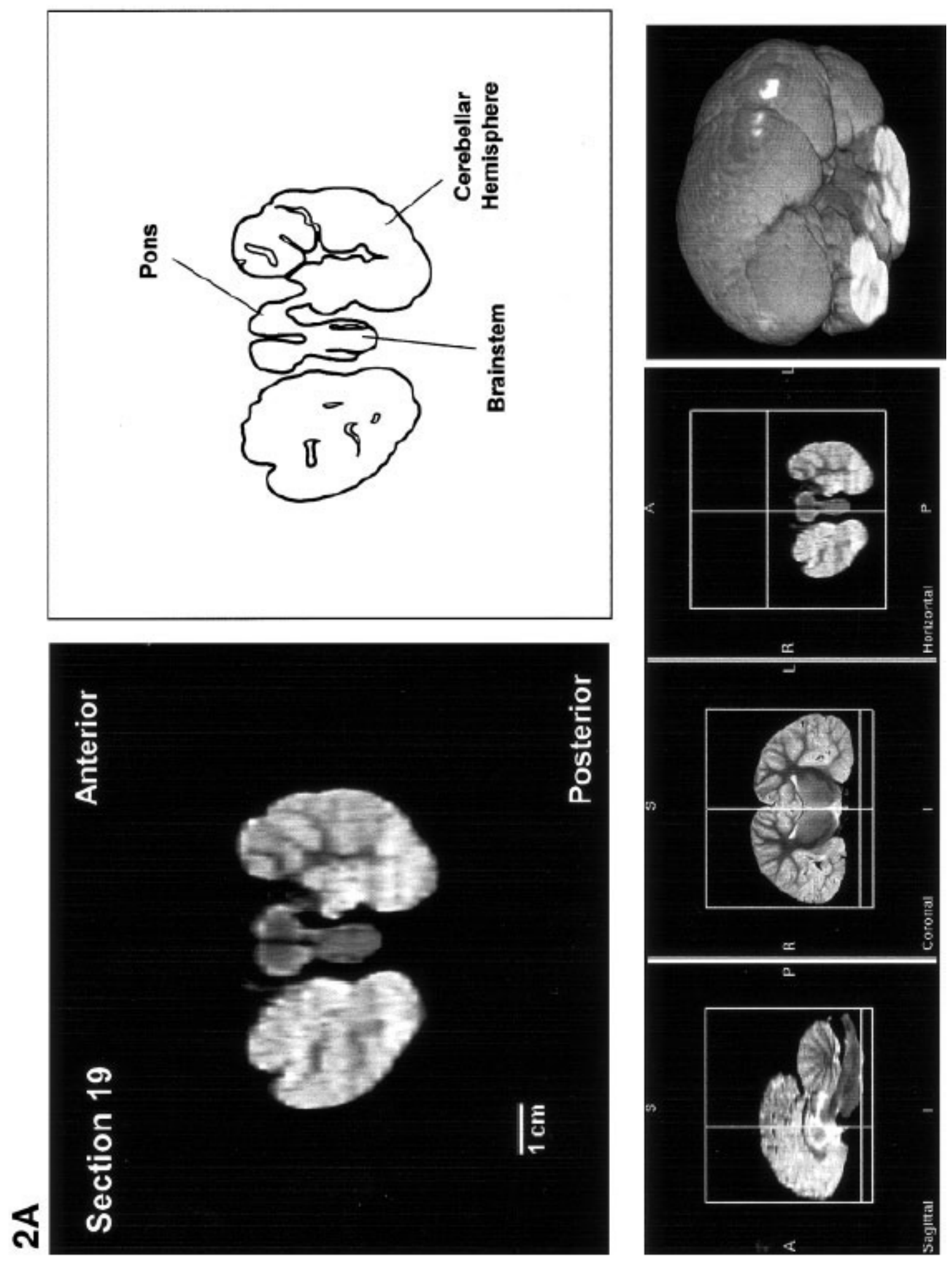
Figure 2. (continued)
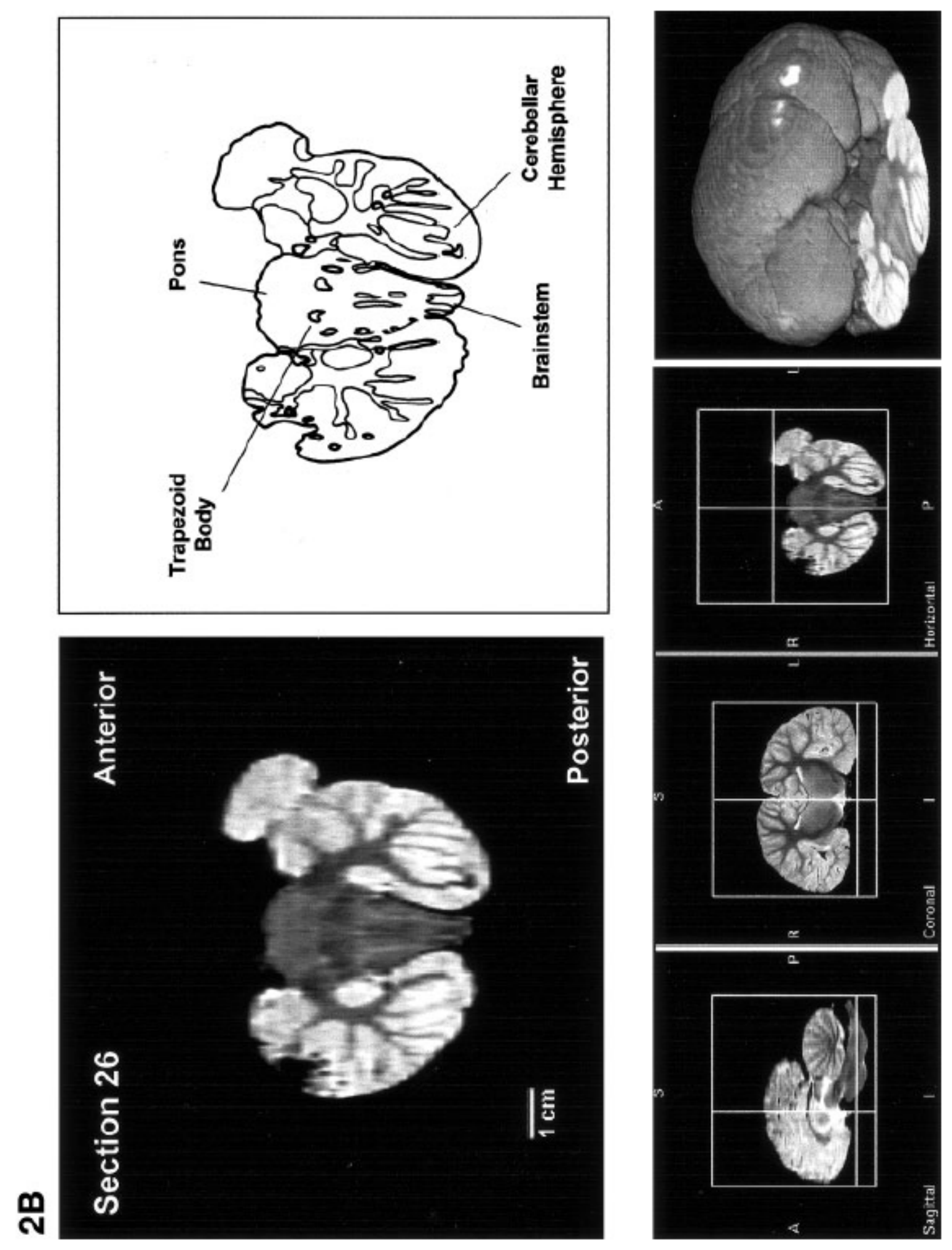
Figure 2. (continued)
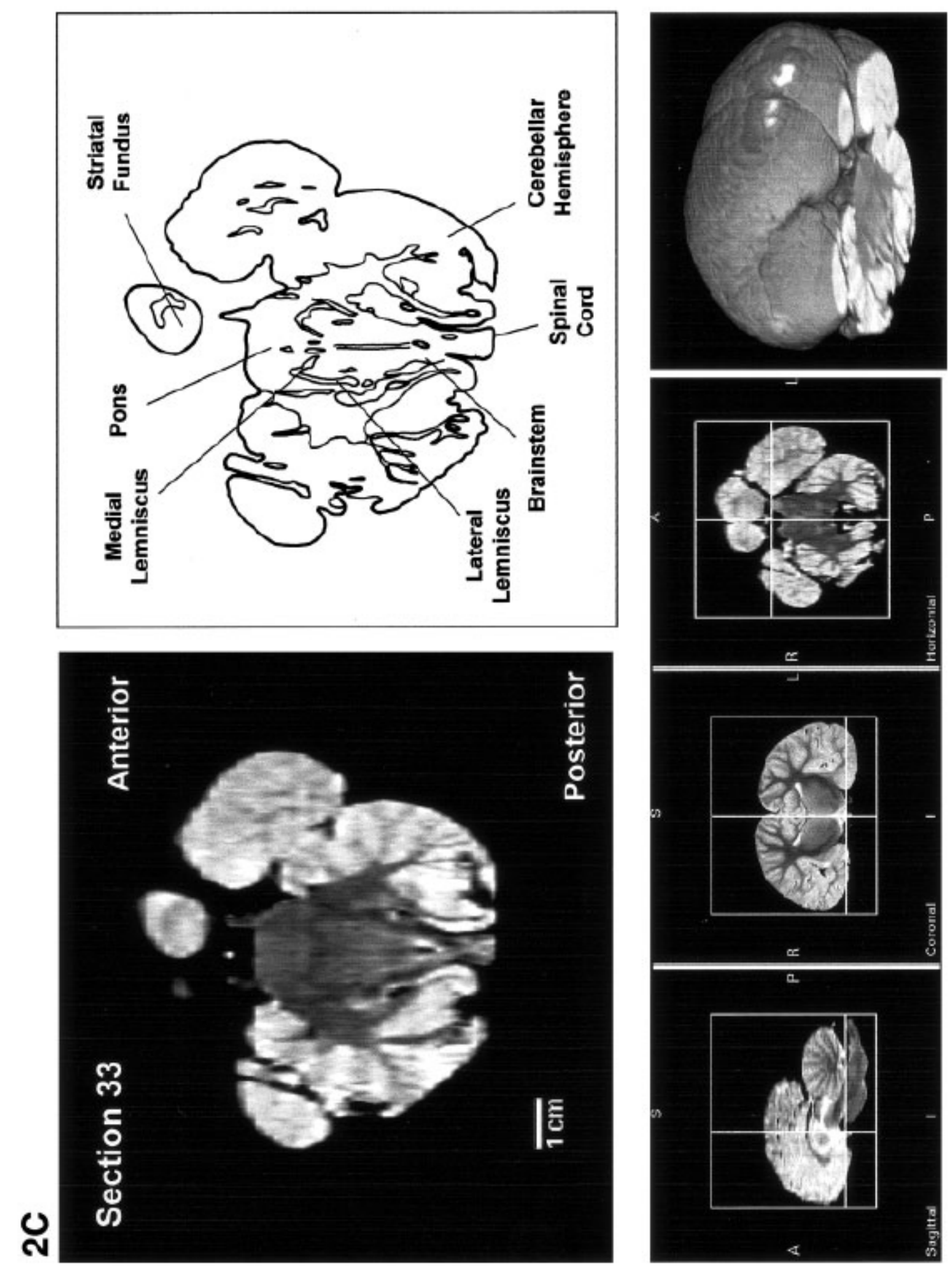
Figure 2. (continued)
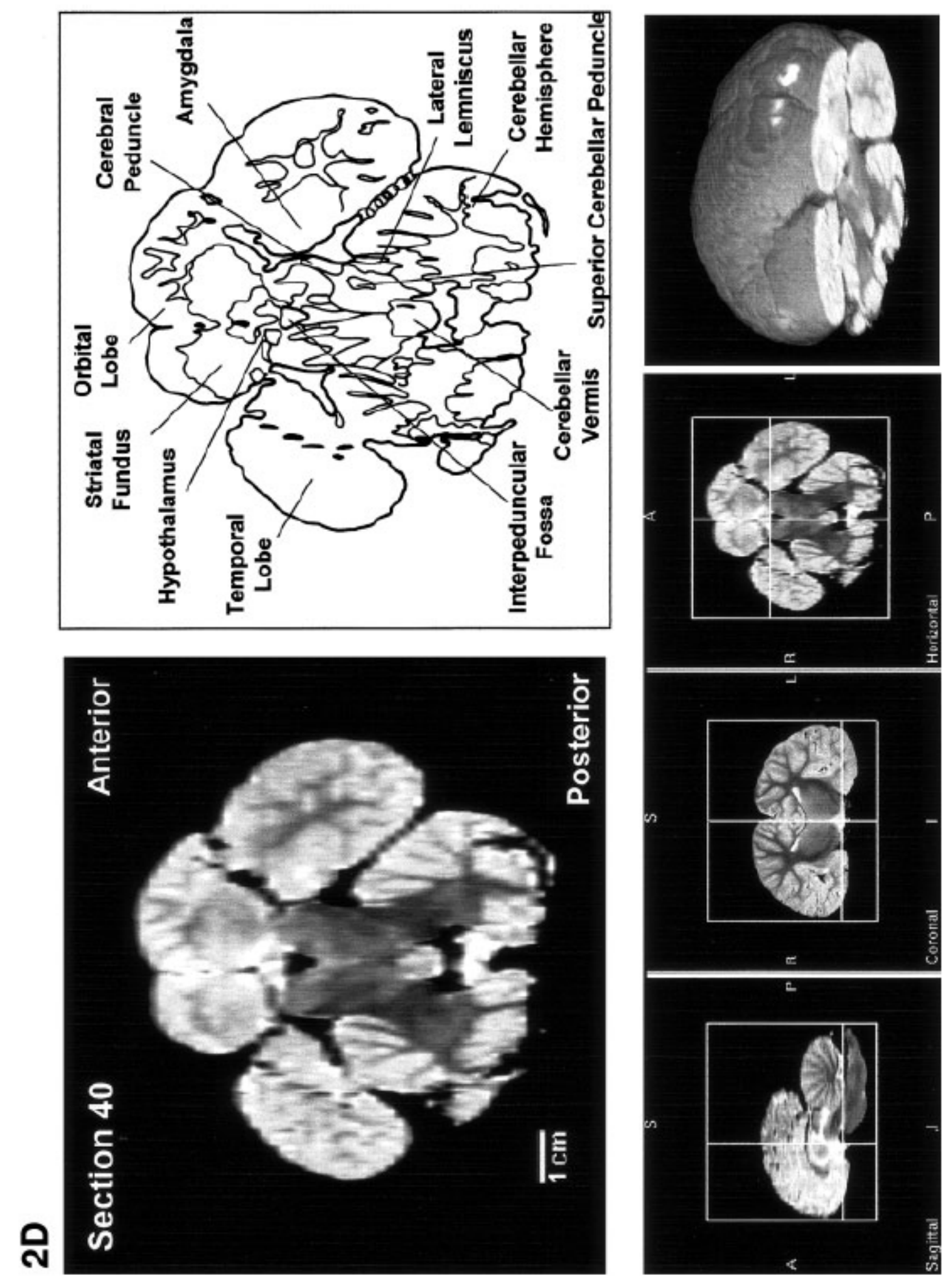
Figure 2. (continued)
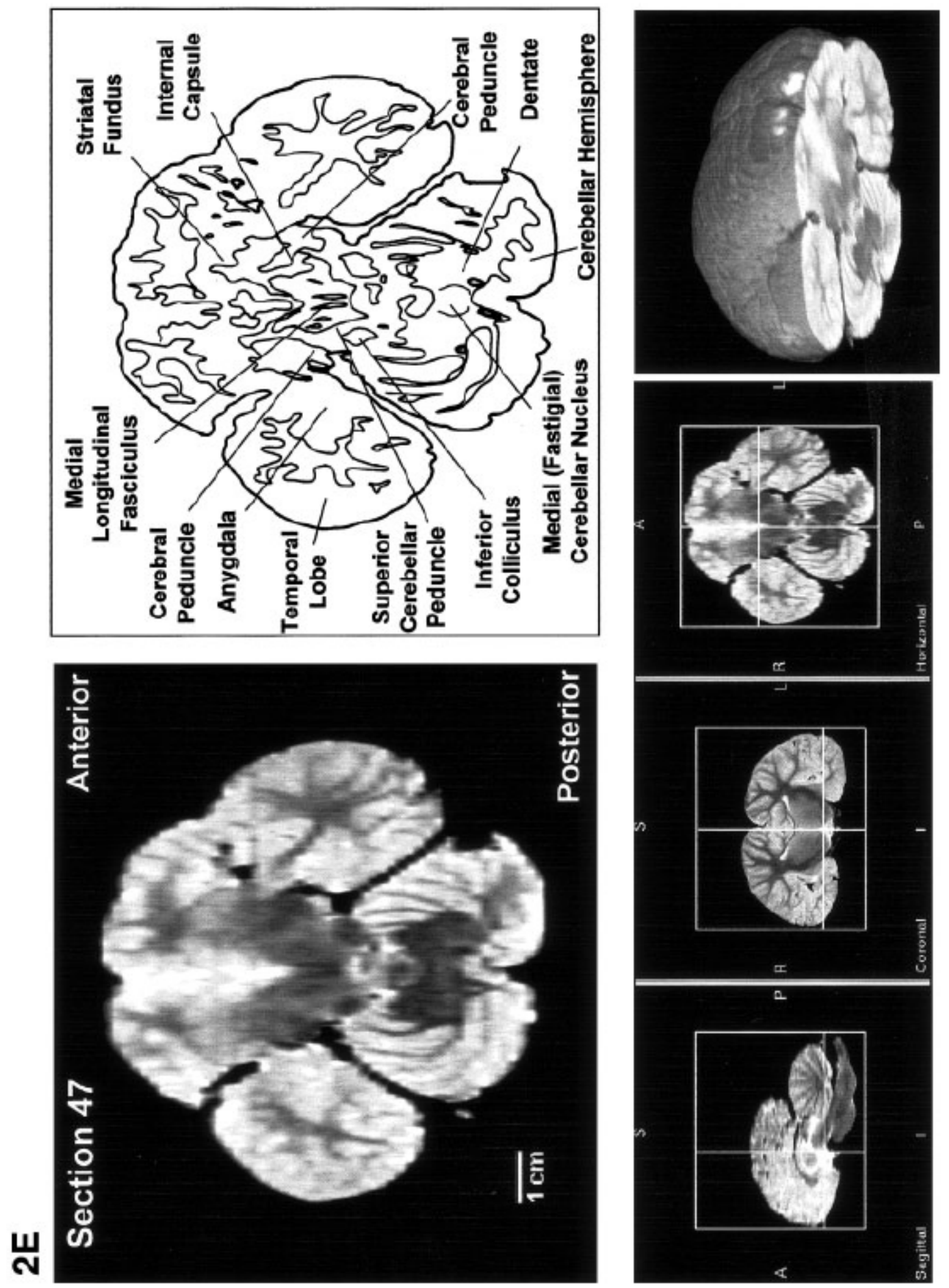
Figure 2. (continued)
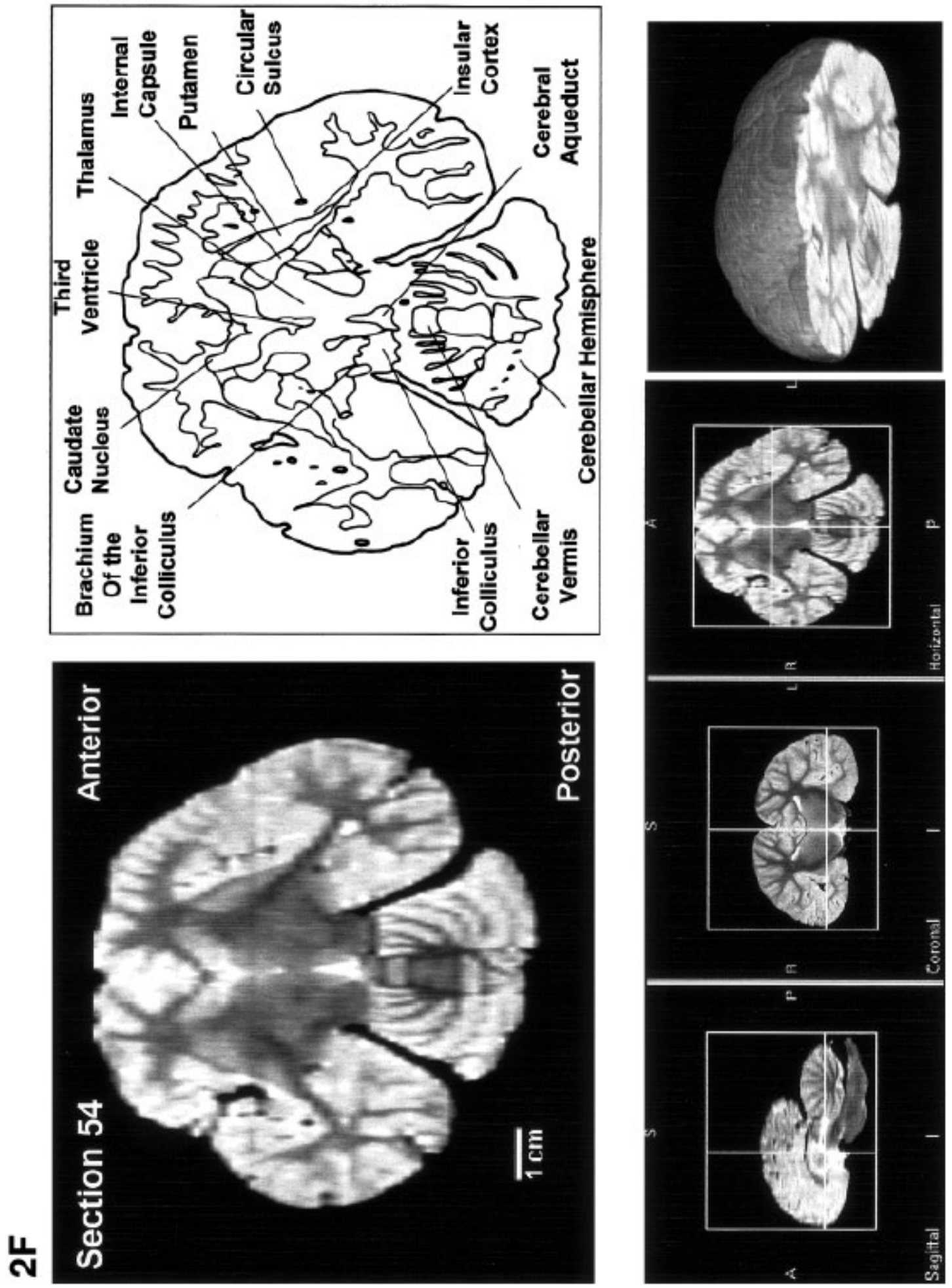
Figure 2. (continued)
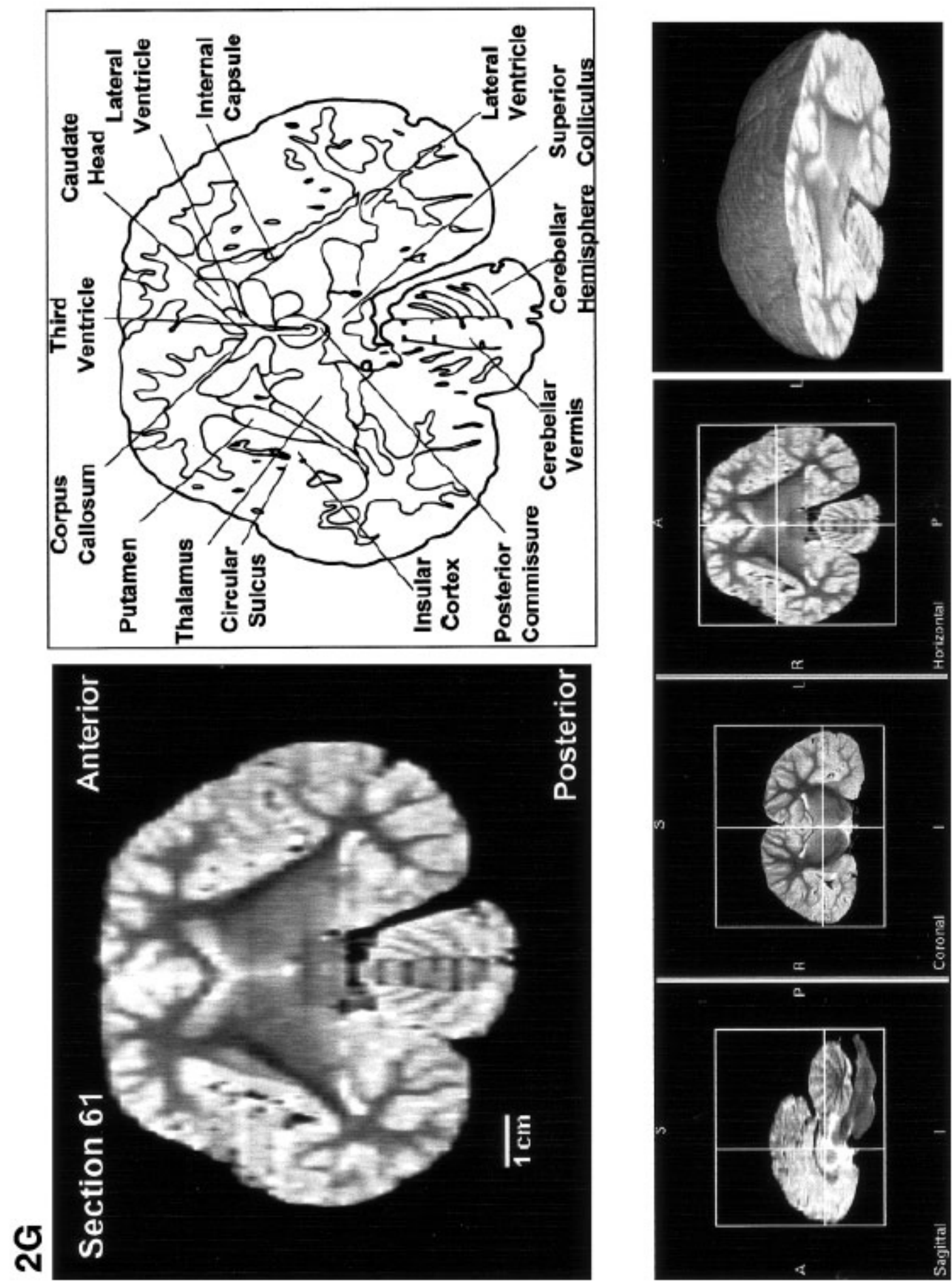
Figure 2. (continued)
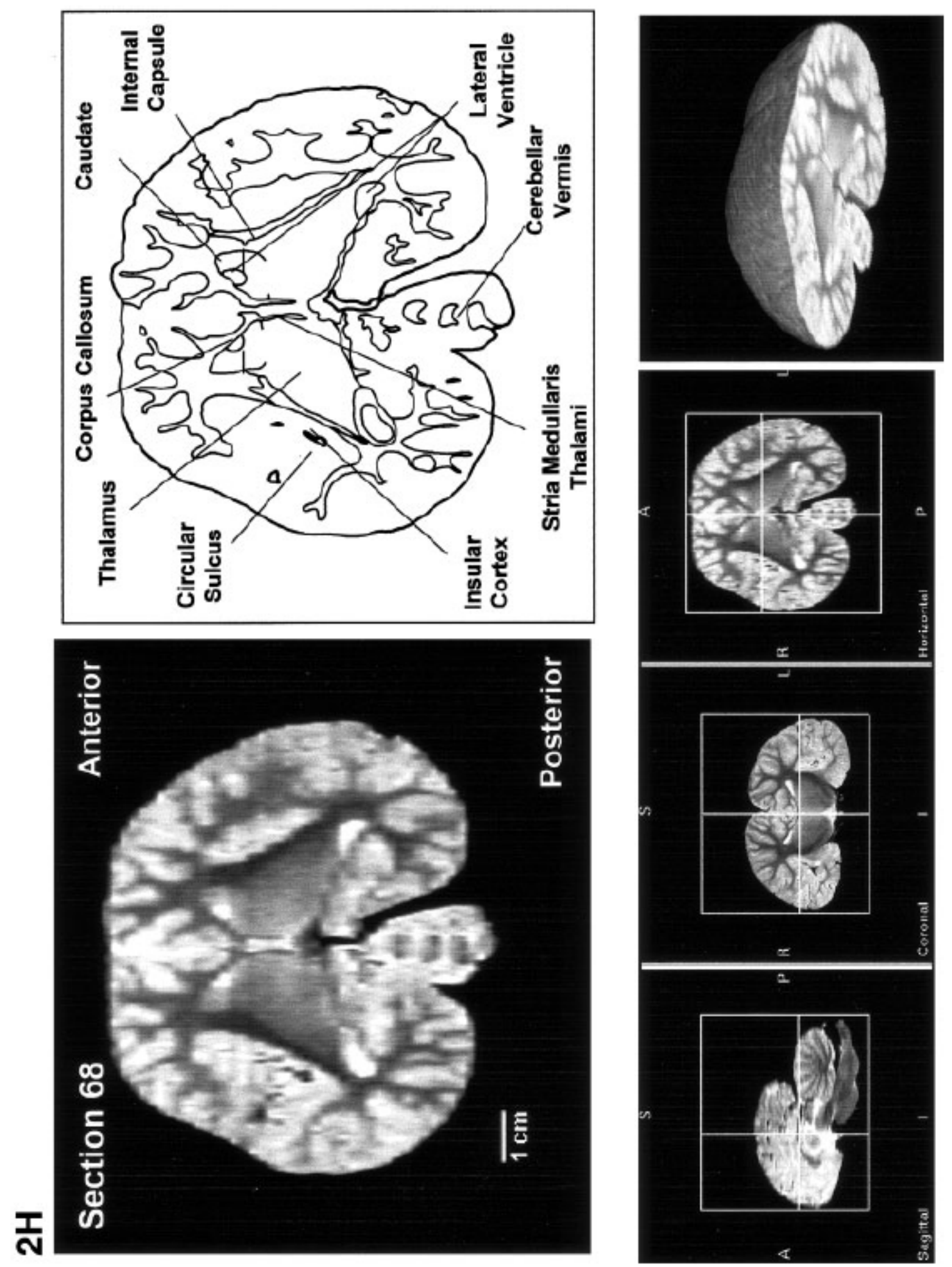
Figure 2. (continued)
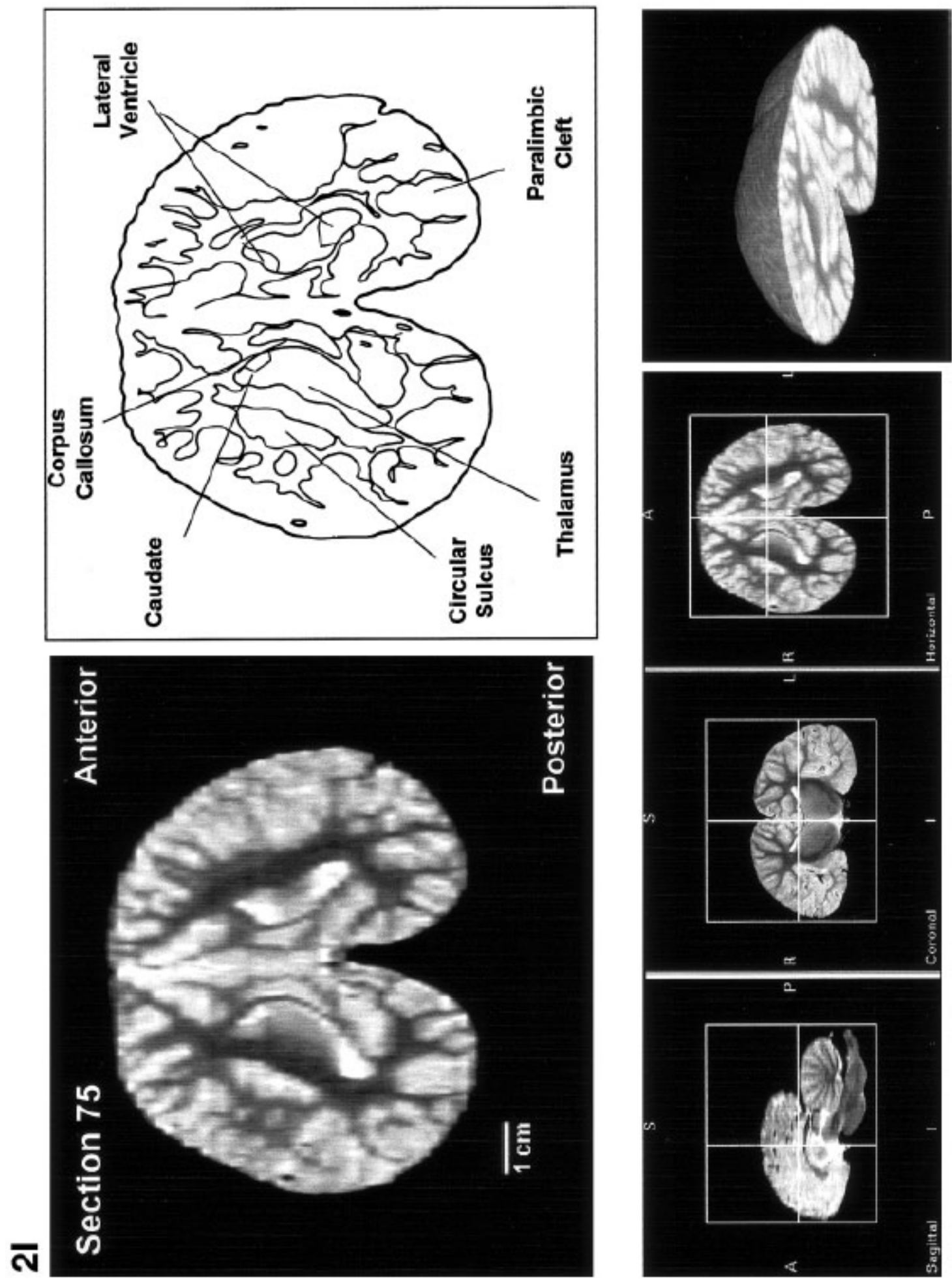
Figure 2. (continued)
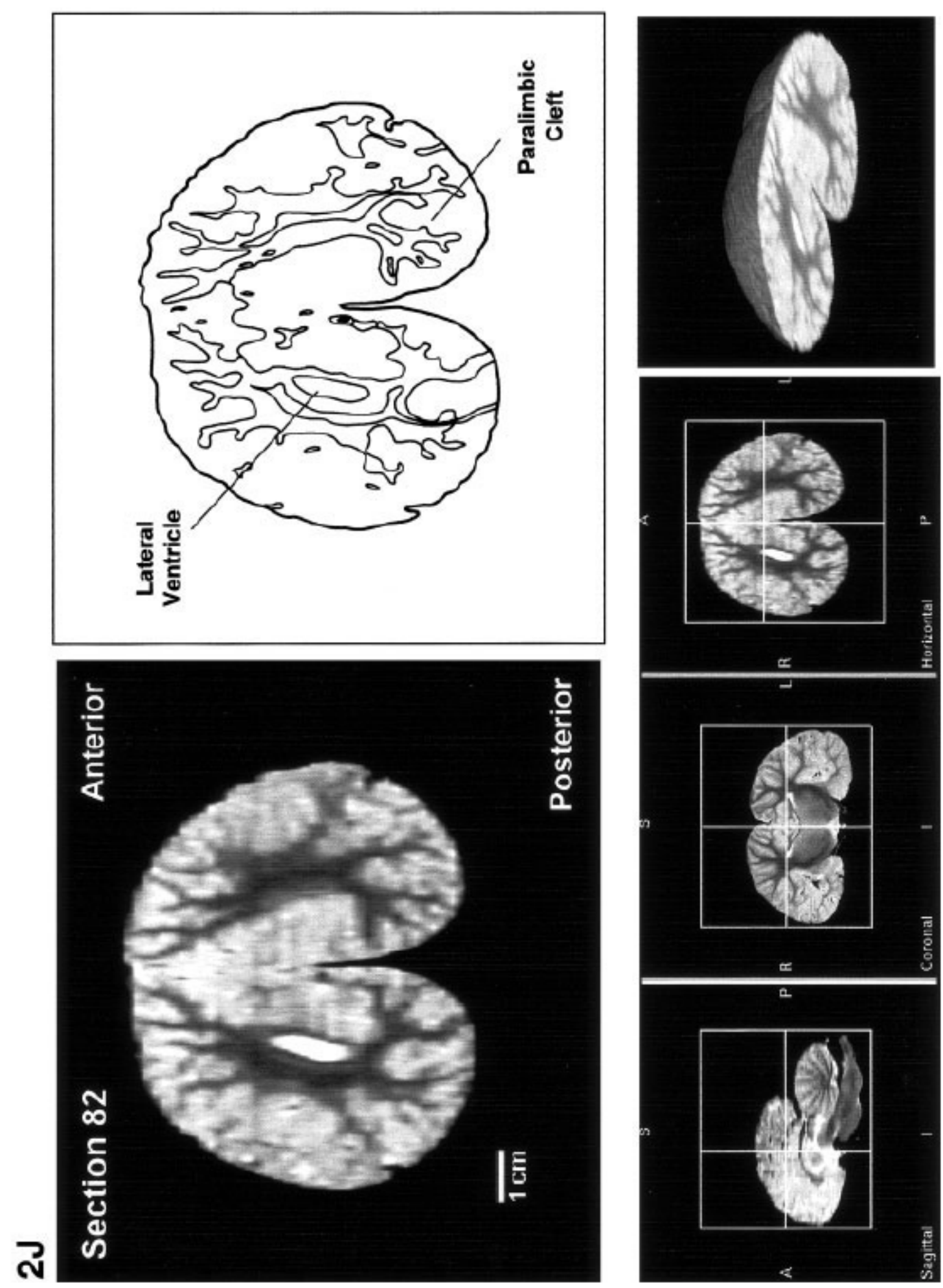
Figure 2. (continued)
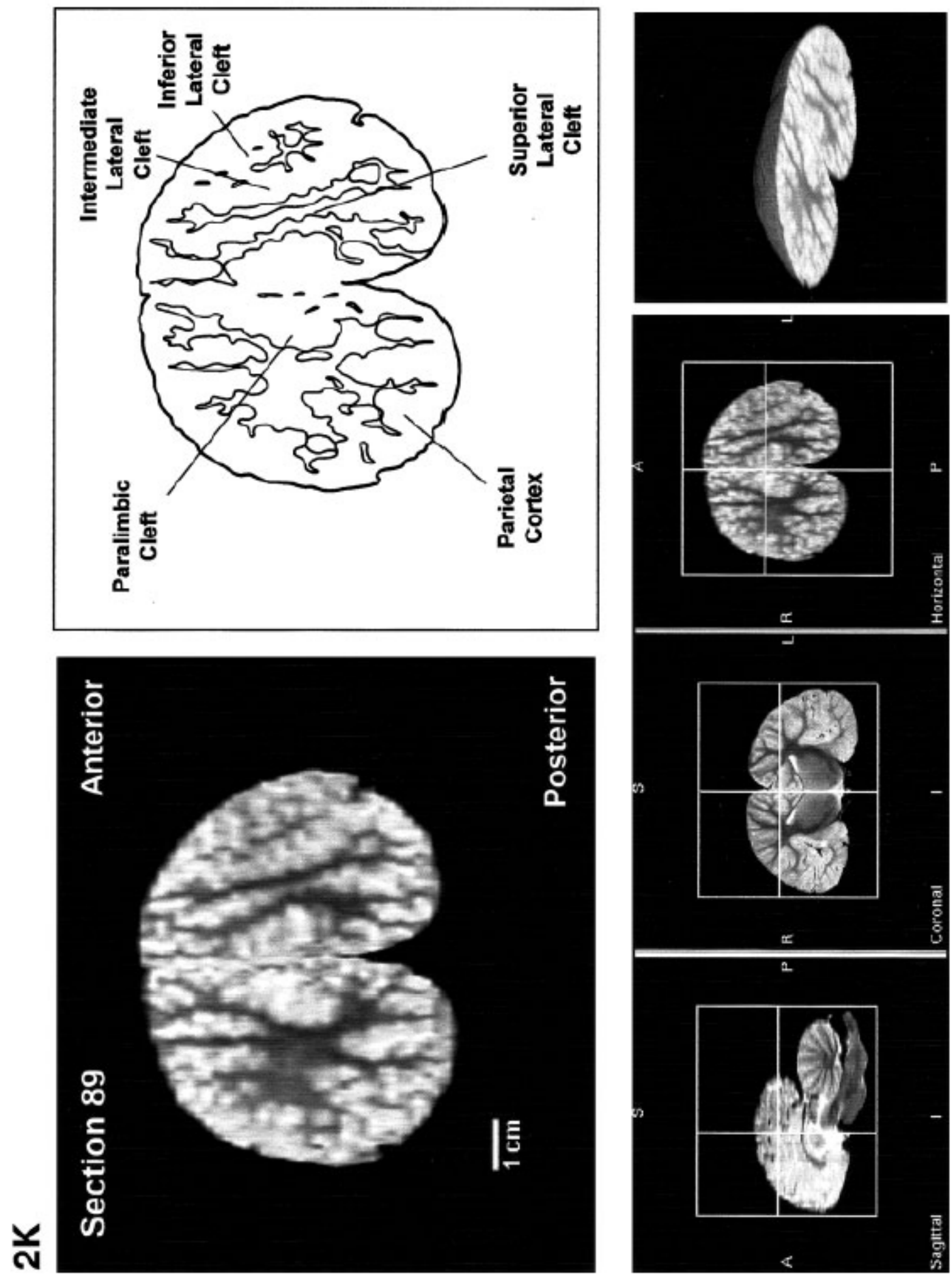
Figure 2. (continued)
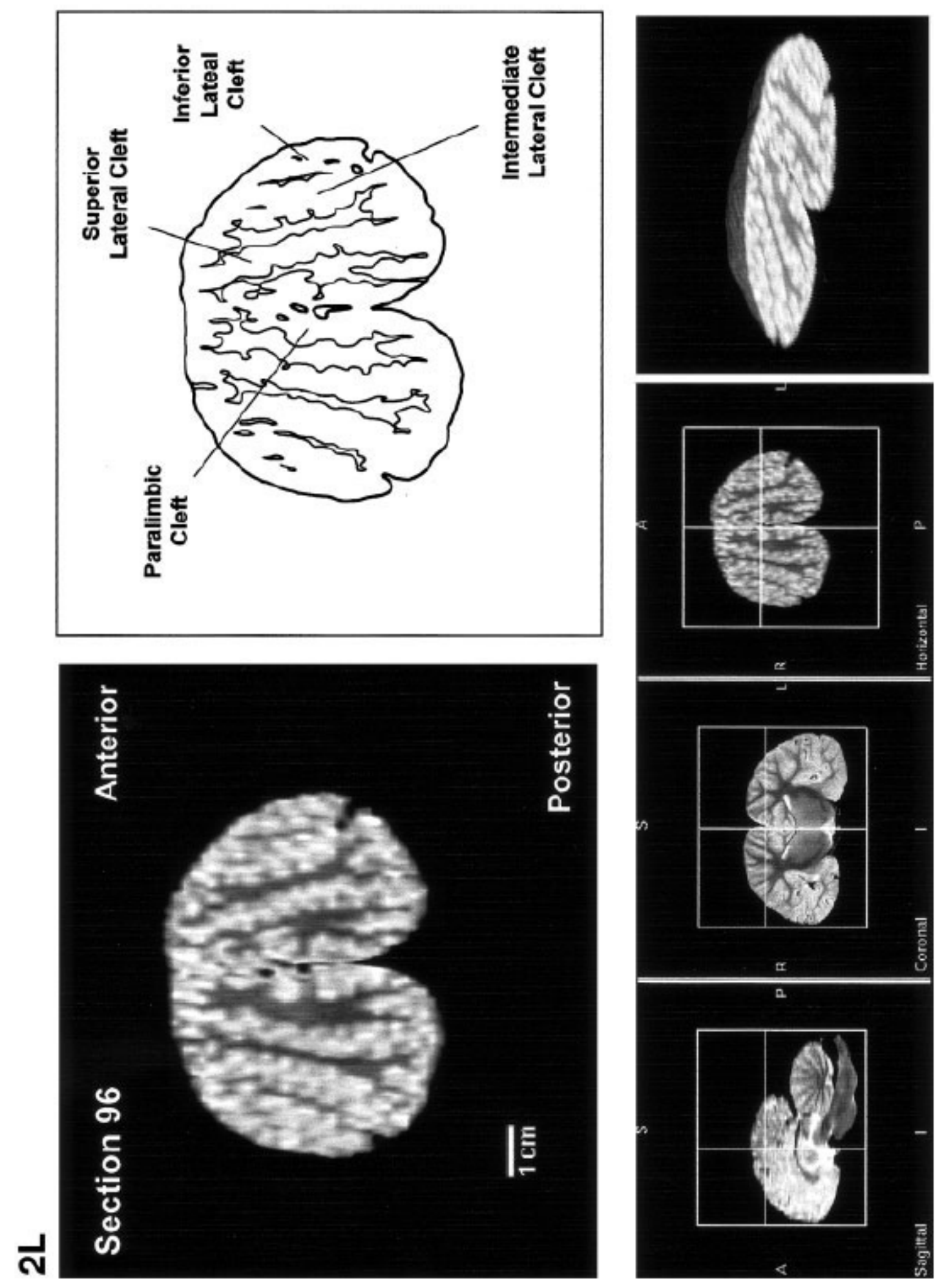
Fig. 3. a-I: Phocoena phocoena. Midline-to-lateral sequence of reconstructed virtual 0.64-mm thick sagittal sections through the left hemisphere at 3.8-mm intervals, a labeled schematic illustration of each section, computer-generated images showing the level at which the section was taken in three orthogonal planes, and a computer-generated three-dimensional reconstruction of the whole brain showing the brain digitally "cut" at the level of the section.
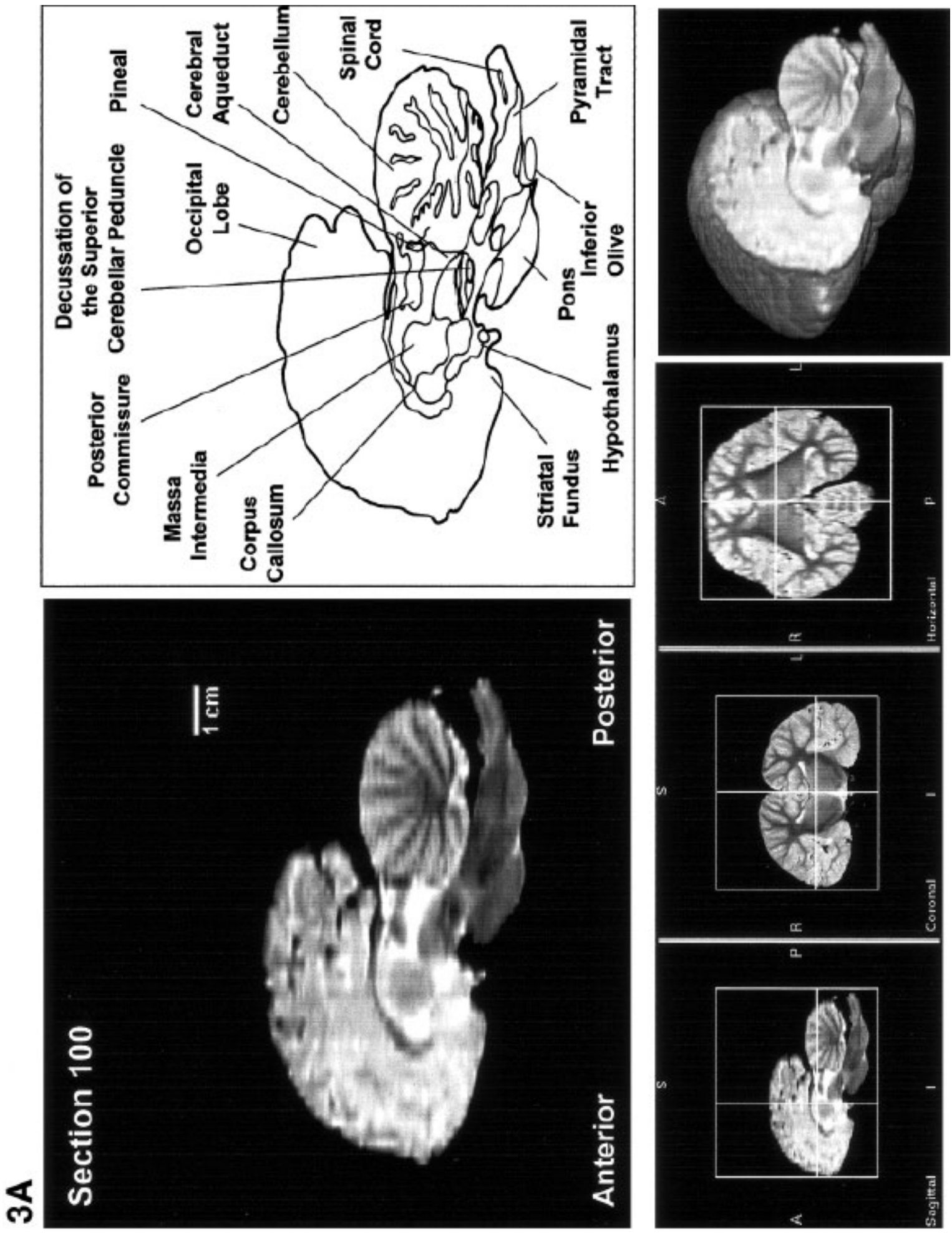
Figure 3. (continued)
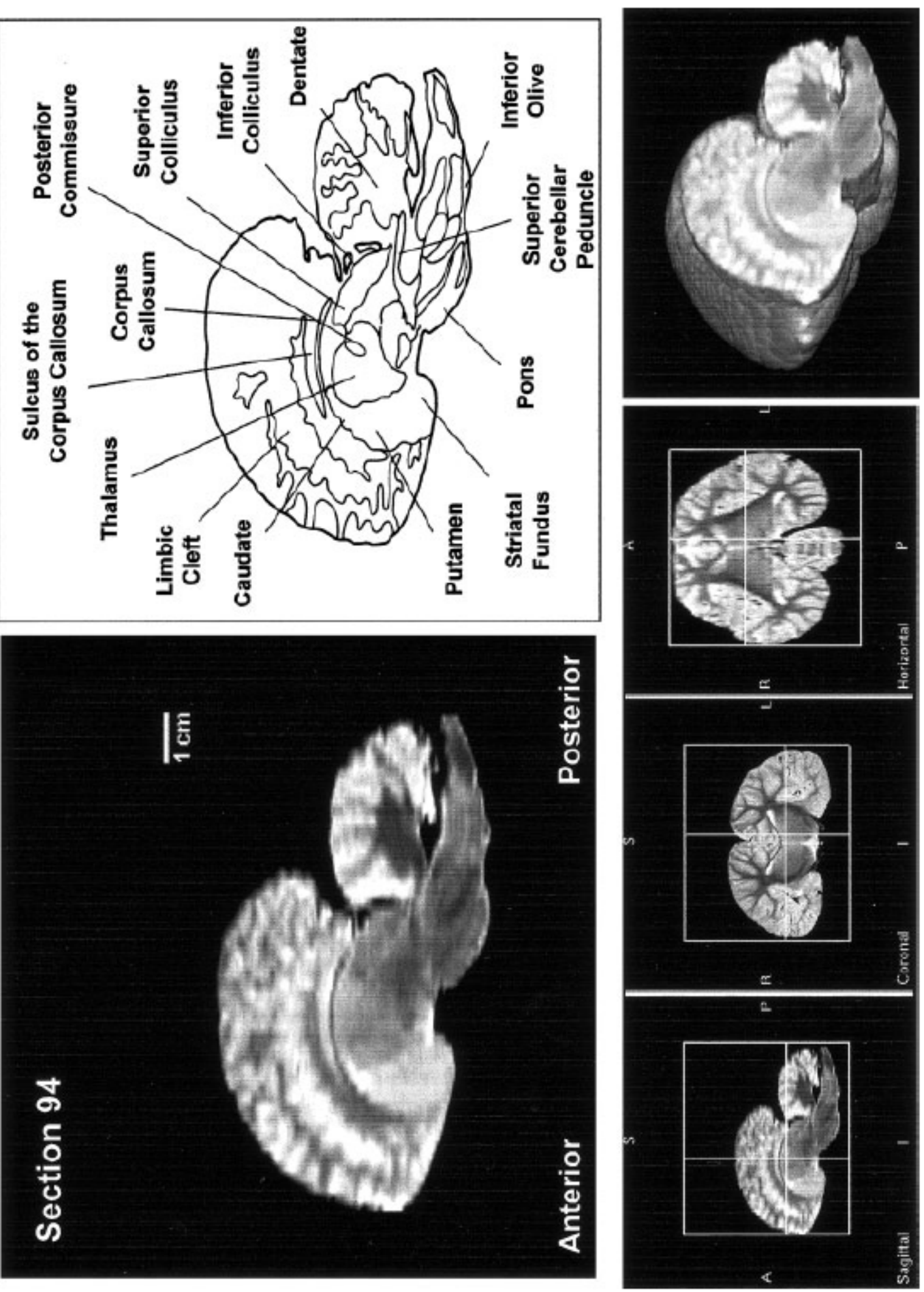
Figure 3. (continued)
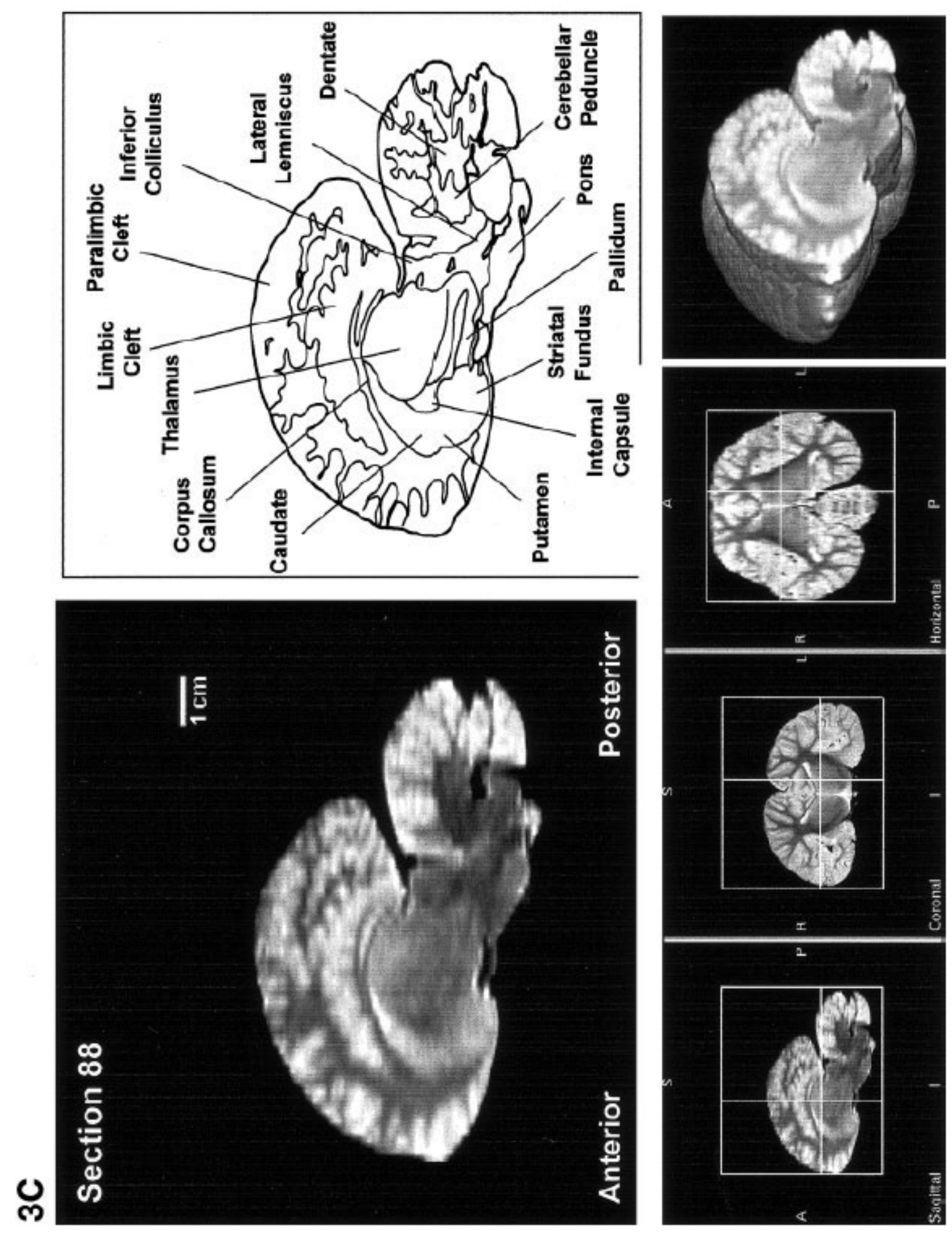
Figure 3. (continued)
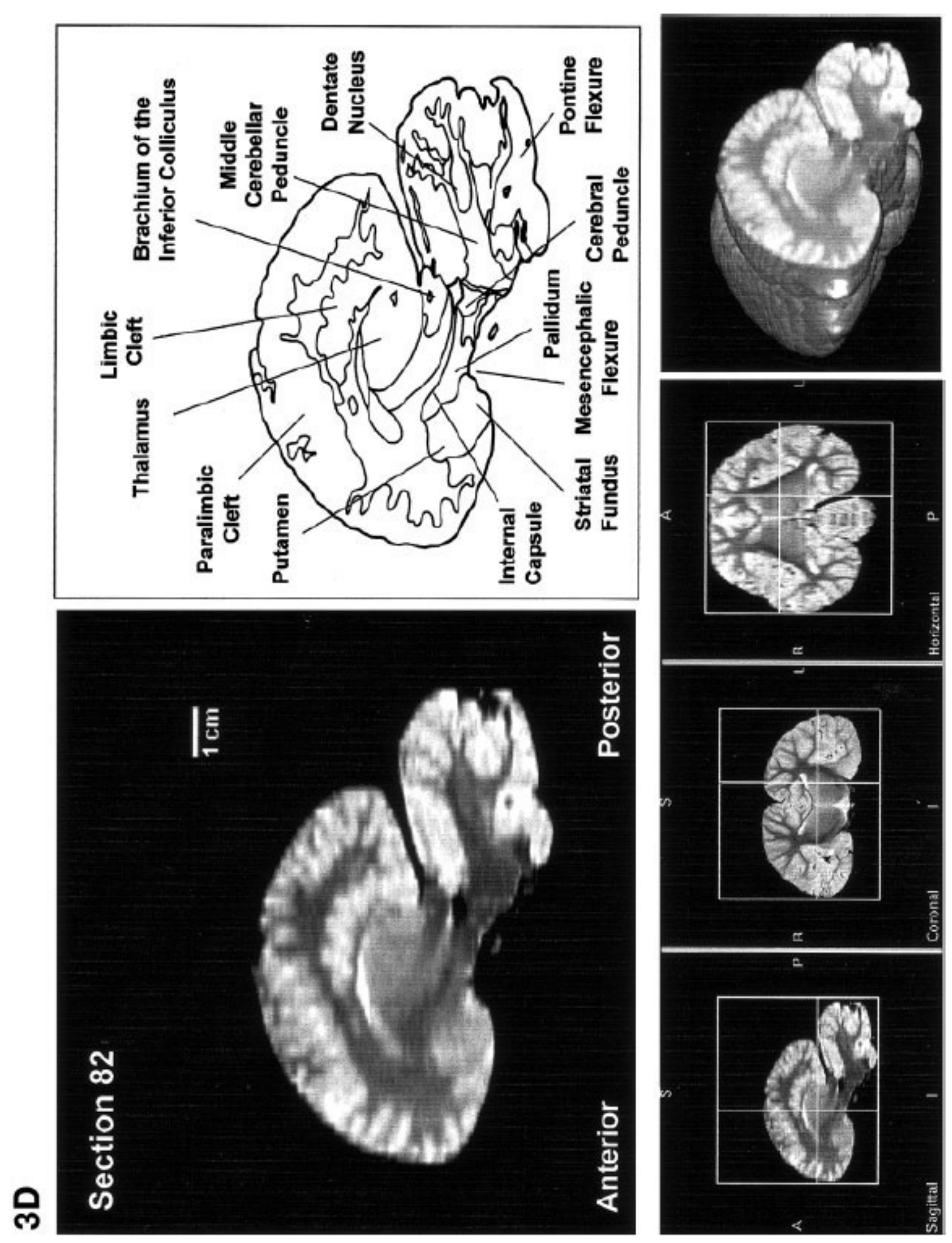
Figure 3. (continued)
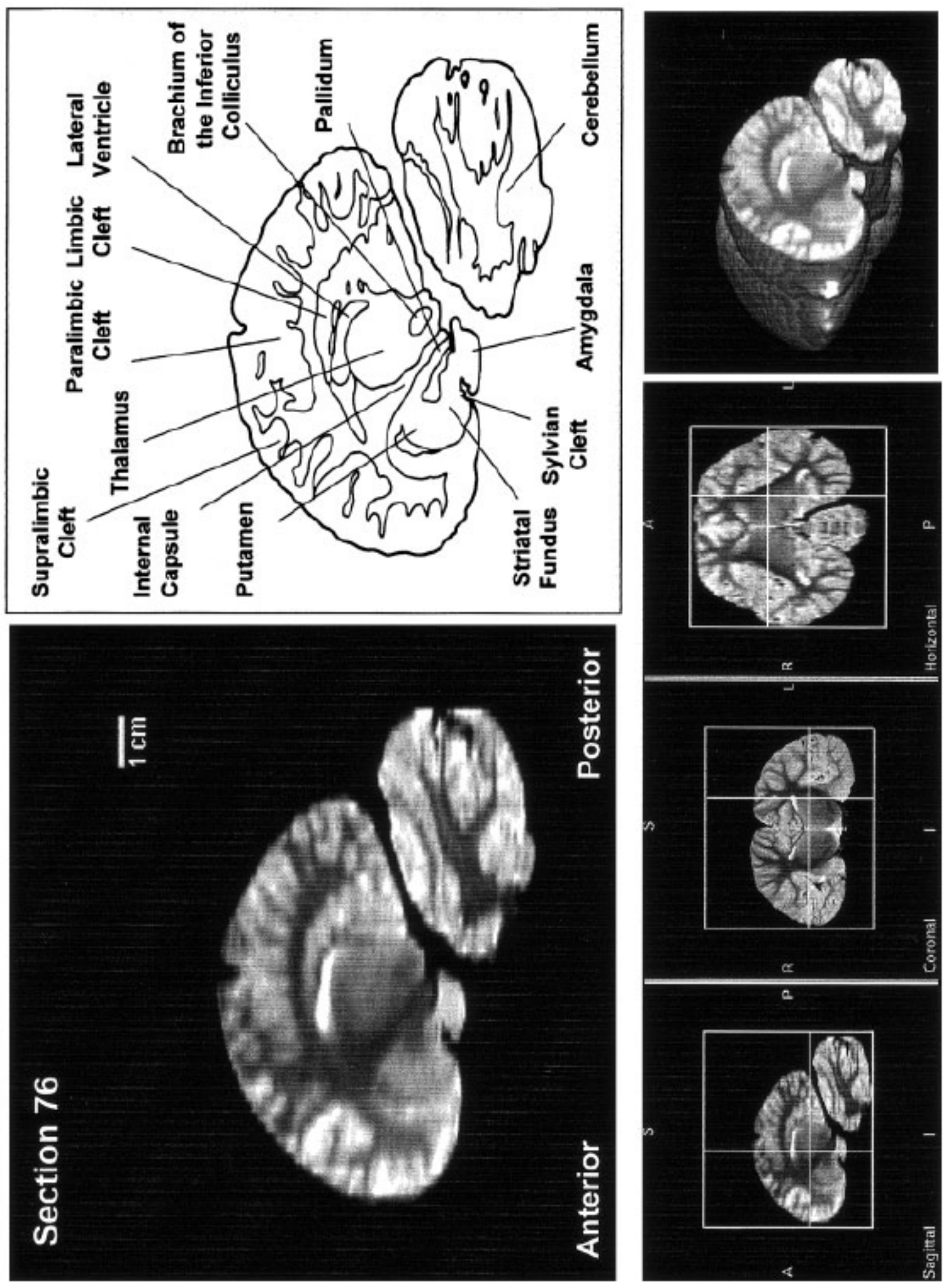
Figure 3. (continued)
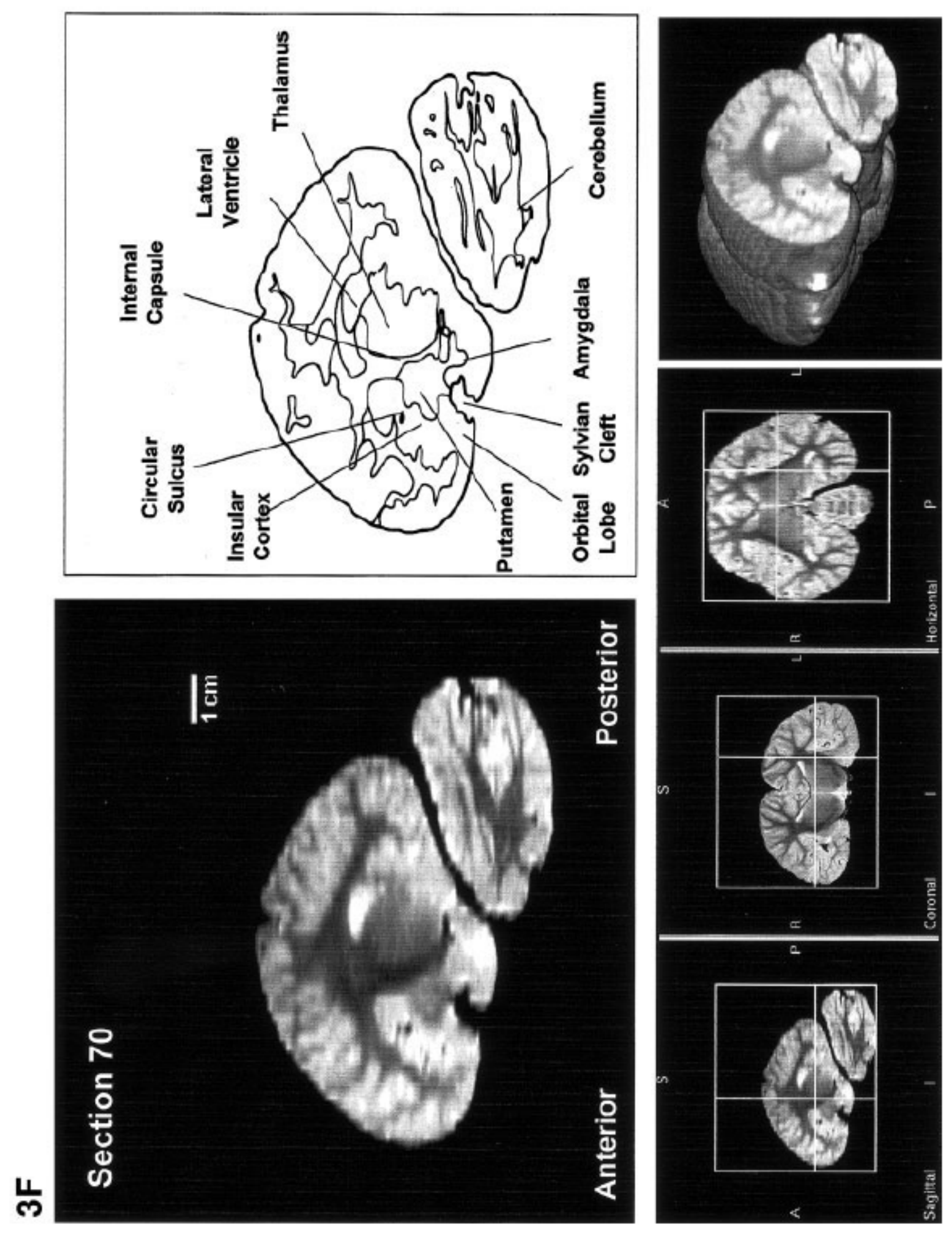
Figure 3. (continued)
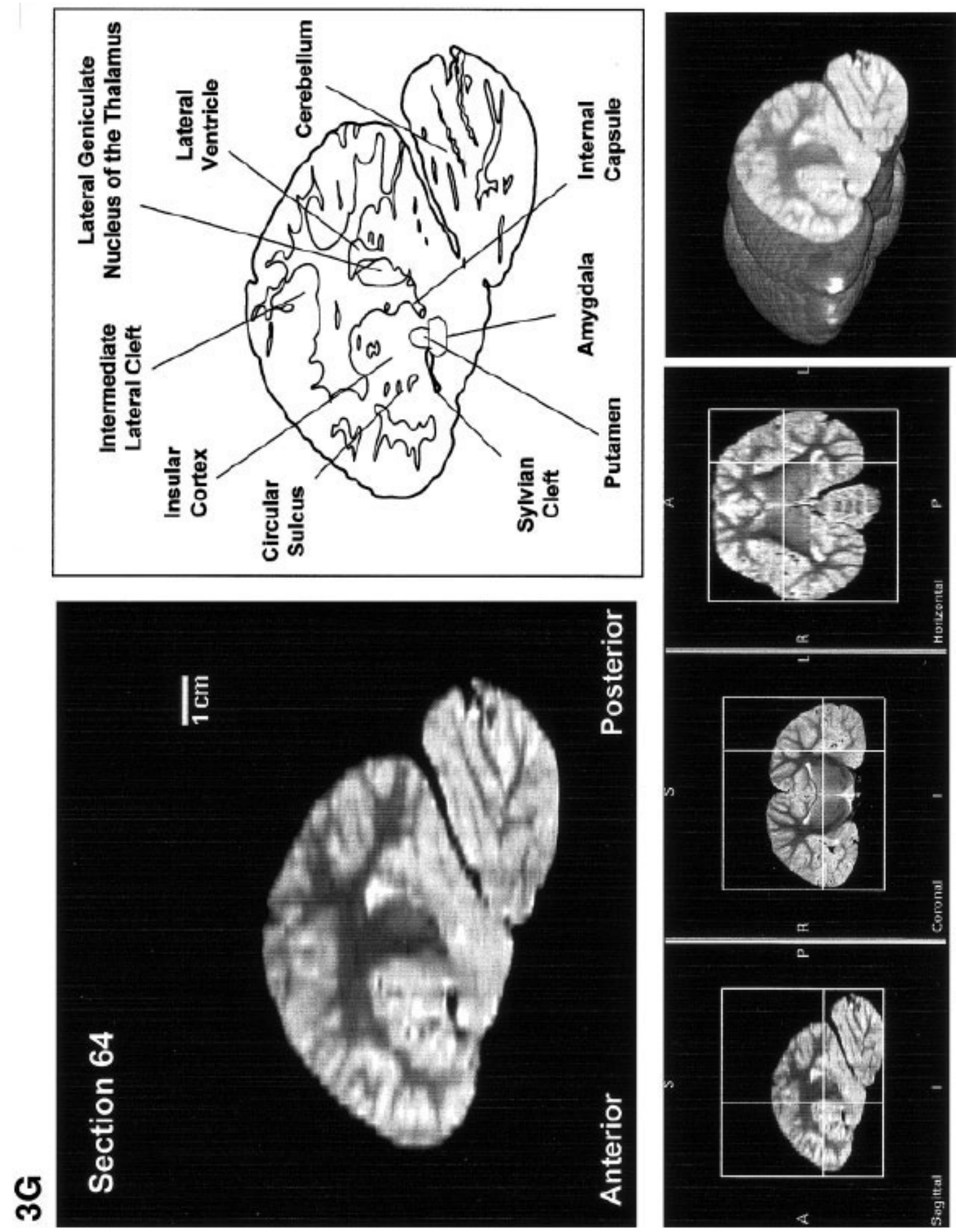
Figure 3. (continued)
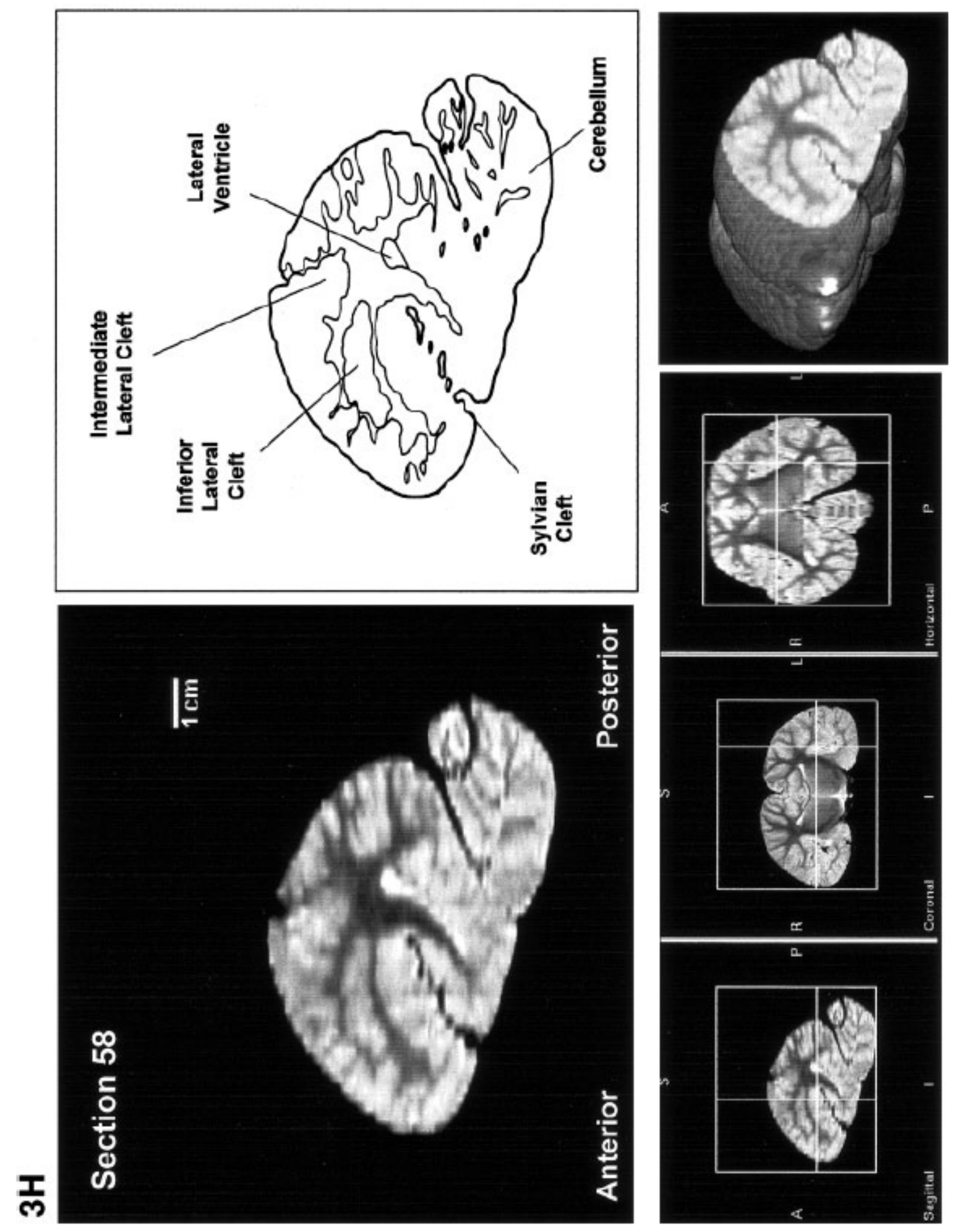
Figure 3. (continued)

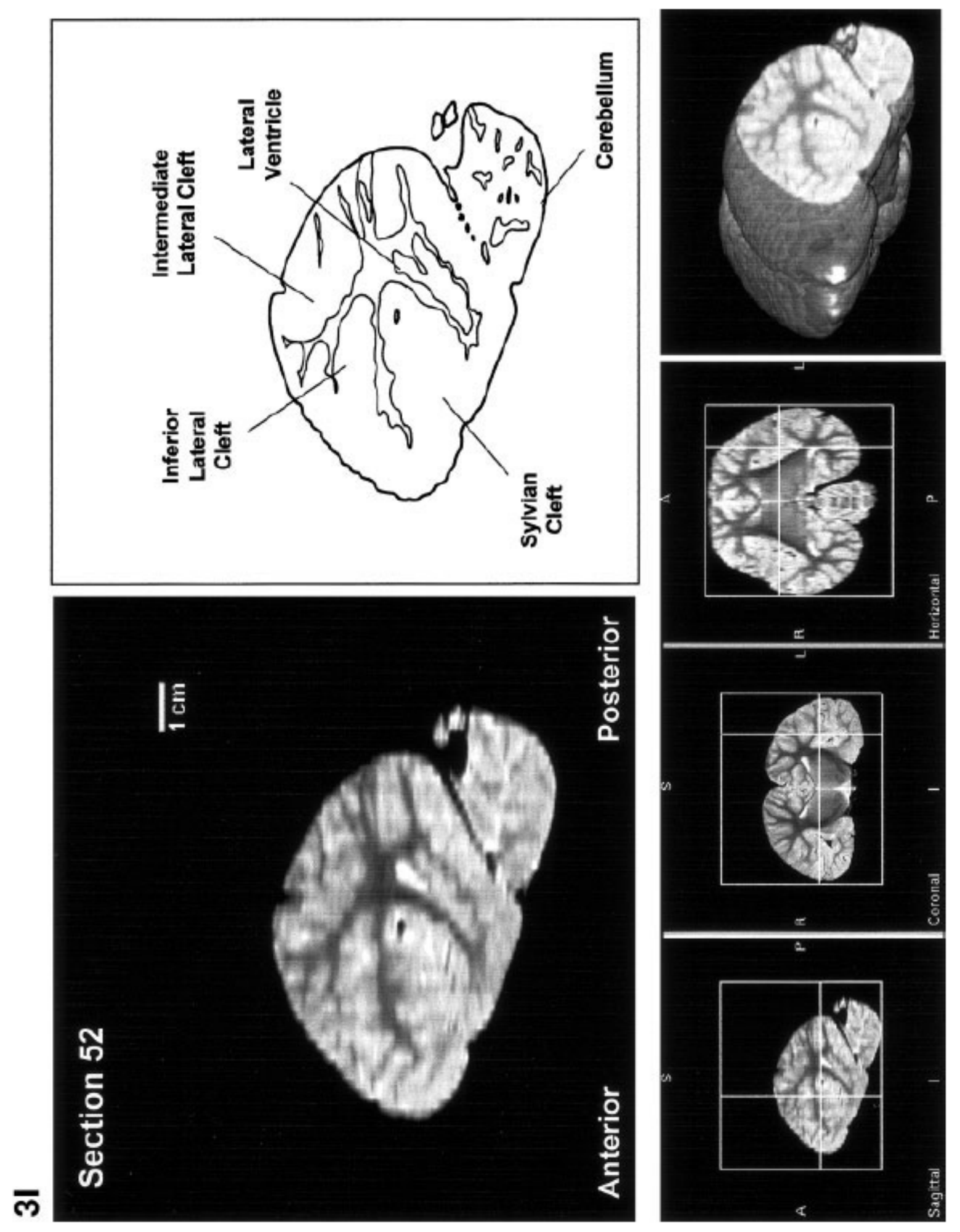


Figure 3. (continued)
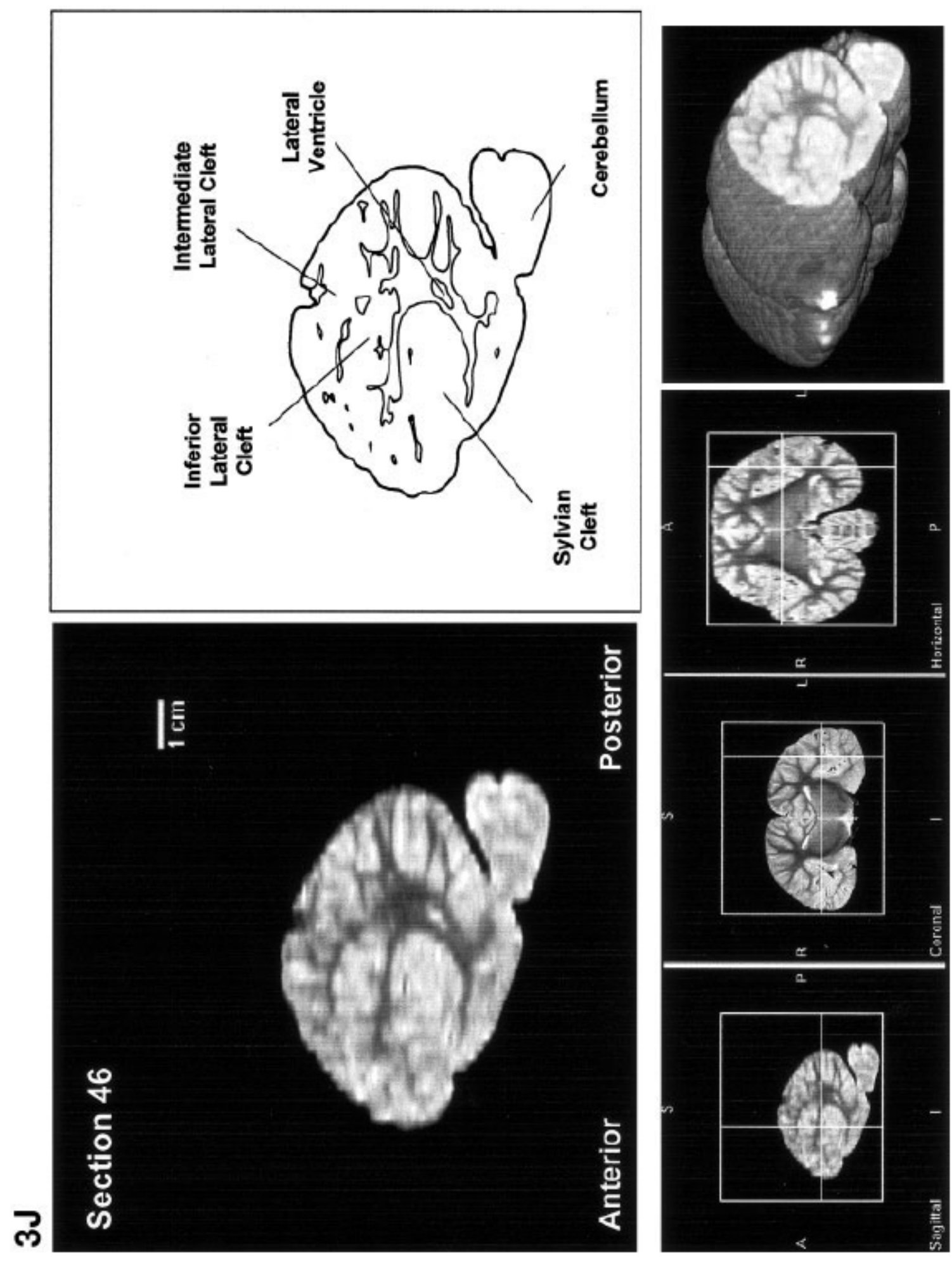
Figure 3. (continued)
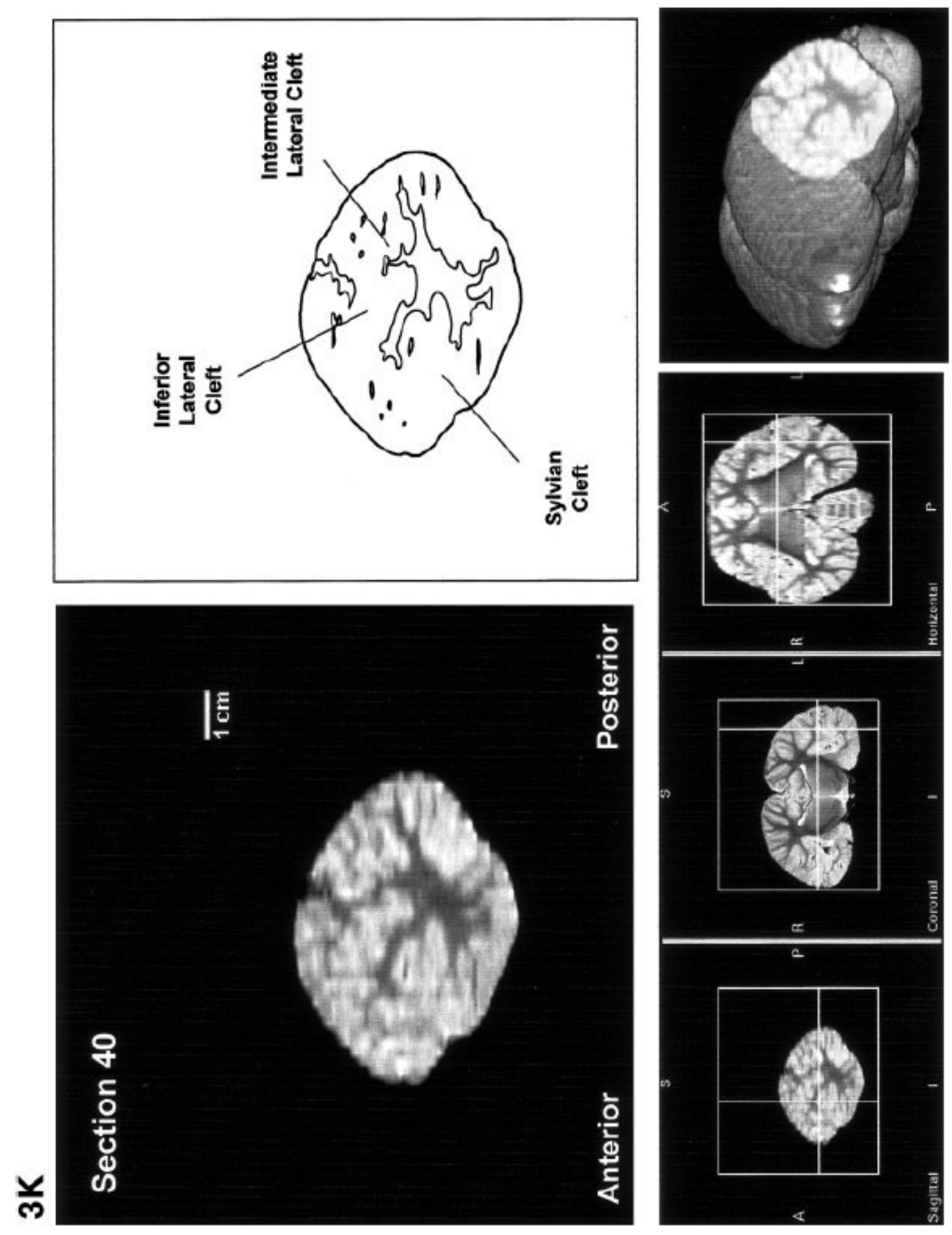
Figure 3. (continued)
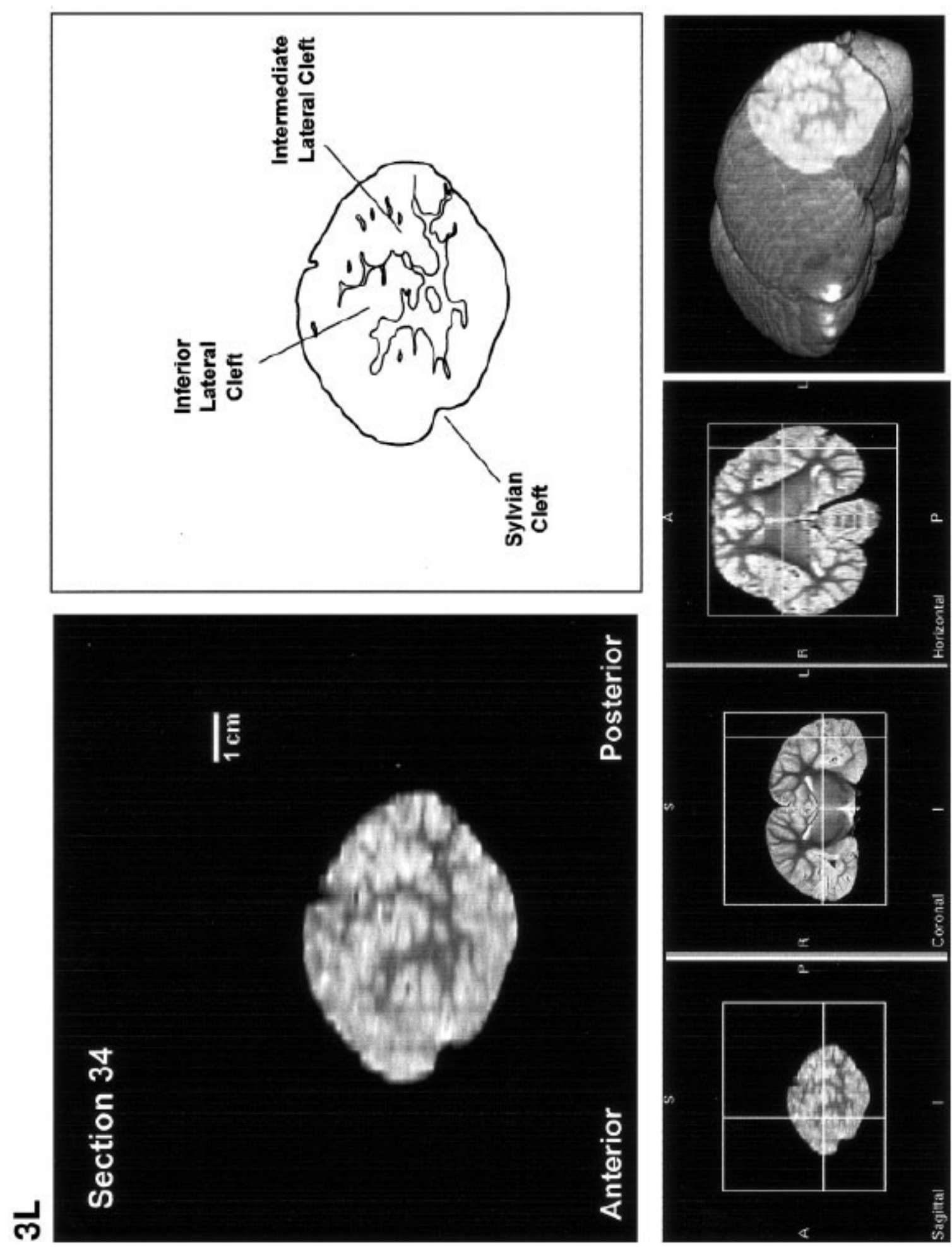
The brains of some odontocete cetacean species have been regularly studied. In particular, the bottlenose dolphin (Tursiops truncatus), a member of the family Delphinidae, has received the most scientific attention (see Marino et al., 2001a). But there exist relatively few studies of the brains of species outside the delphinids. One such species is the harbor porpoise (Phocoena phocoena), a member of the family Phocoenidae. Many aspects of the life history and ecology of the harbor porpoise have been studied over the years (Stuart and Morejohn, 1980; Gaskin et al., 1984; Recchia and Read, 1989; Read, 1990; Sorensen and Kinze, 1994; Read and Hohn, 1995; Palka et al., 1996; Read and Tolley, 1997; Read and Westgate, 1997; Walton, 1997; McLellan et al., 2002) and studies of the harbor porpoise brain do exist. These range from analyses of overall brain growth (Marino, 1999), relative brain size (Marino, 1998), and prenatal brain and nerve morphogenesis (Oelschlager and Buhl, 1985; Buhl and Oelschlager, 1988) to descriptions of overall structure and neuronal morphology and distribution (Morgane et al., 1980; Revishchin and Garey, 1990, 1993; Hof et al., 1995; Oelschlager and Oelschlager, 2001). Also, there have been several studies of cortical functional mapping in the harbor porpoise (Sokolov et al., 1972; Supin et al., 1978; Popov et al., 1986). Despite the particularly elegant body of work by Oelschlager and others, there are no existing neuroanatomical articles on the harbor porpoise brain that contain labeled sequential images through the three orthogonal spatial planes because of the difficulties associated with the histological preparation of such large brain specimens. Magnetic resonance imaging (MRI) offers a means of observing the internal structure of these large brains where traditional methods of embedding, sectioning, staining, mounting, and microscopic examination are not practical. Furthermore, MRI offers the opportunity to observe internal structures in their precise anatomical positions because the fixed whole brain is kept intact during the scanning, therefore minimizing the spatial distortions associated with many histology methods. This article represents the first MRI-based anatomically labeled threedimensional description of the harbor porpoise brain.

\section{MATERIALS AND METHODS}

\section{Specimen}

The specimen is the postmortem brain of a subadult male harbor porpoise (Phocoena phocoena) that stranded alive in March 1999 in Long Island Sound, New York. After a brief rehabilitation at the Riverhead Foundation the porpoise was transferred to Mystic Aquarium in Mystic, Connecticut, in June 1999. Several bouts of poor health ensued over the following months, including eruptions of multiple skin lesions that were present at the time of stranding and severe anemia and leukopenia. In April 2000 the animal was euthanized. Necropsy results showed verminous pneumonia and other serious health problems.

The total body length of the porpoise was $127 \mathrm{~cm}$. Total body weight and maximum girth were $29.8 \mathrm{~kg}$ and $78 \mathrm{~cm}$, respectively. Normative values for age, body length, and body weight at weaning and sexual maturity from the literature places the life history stage of this specimen between weaning and sexual maturity (Stuart and Morejohn, 1980; Sorensen and Kinze, 1994; Gaskin et al., 1984; Read and Hohn, 1995; Read and Tolley, 1997). The best estimate of the age of this specimen, based on its height and weight and on estimates of caretakers at Mystic Aquarium (G. Sirpenski, pers. commun.) is 2 years.

The anterior-posterior length of the brain was $102 \mathrm{~mm}$. The bitemporal width was $116 \mathrm{~mm}$. The height of the brain was $65 \mathrm{~mm}$. The brain was immersed in formalin for 18 months prior to scanning.

\section{MRI Protocol}

MR images of the entire brain were acquired in the coronal plane with a 1.5 T Philips NT scanner (Philips Medical System, The Netherlands) at Emory University School of Medicine. Imaging protocol parameters 
were: slice thickness - $2 \mathrm{~mm}$, slice interval - $0 \mathrm{~mm}$, TR - $3000 \mathrm{msec}$, TE - $22 \mathrm{msec}$, field of view - $160 \mathrm{~mm}$, matrix - $256 \times 256$ pixels. The specimen was scanned with the ventral side down in the human head coil.

\section{Three-Dimensional Reconstruction and Reformatting}

A computer-generated 3D model was created from 51 2-mm thick originally acquired coronal scans using the software program VoxelView (Vital Images, Plymouth, MN) at the Laser Scanning Microscopy Laboratory at Michigan State University. The 3D rendered model was then digitally resectioned in orthogonal planes to produce corresponding virtual section series in the horizontal (110 0.6-mm thick virtual sections) and sagittal (180 0.64-mm thick virtual sections) planes.

\section{Volume Measurements}

Whole-brain volume was measured with the image analysis software program Scion IMAGE for Windows (PC version of NIH IMAGE) using manually defined areas from successive slices which were integrated to arrive at a volume estimate. Volumetric estimates were converted to weight units by multiplying the volume of the structure by the specific gravity of brain tissue or $1.036 \mathrm{~g} / \mathrm{cm}^{3}$ (Stephan et al., 1981).

\section{Anatomical Labeling and Nomenclature}

All identifiable brain structures of the specimen were labeled in the originally acquired coronal plane images as well as in the images from the virtual sectioned brain in the sagittal and horizontal planes. The MR images of the porpoise brain were compared with the published photographs and illustrations of the bottlenose dolphin brain from Morgane et al. (1980), as well as published neuroanatomical atlases based on MRI scans of an adult bottlenose dolphin brain and an adult common dolphin brain (Marino et al., 2001a, 2002). Images were also compared with data from a study of harbor porpoise brain morphogenesis by Buhl and Oelschlager (1988). Nomenclature is based upon Marino et al. (2001a) and Morgane et al. (1980). Additionally, scans were also compared with a complete alternate series of sections of the bottlenose dolphin brain stained, respectively, for cell bodies (Nissl method), and for myelinated fibers in the same three orthogonal planes (coronal or transverse, sagittal, and horizontal). These stained section series are from the Yakovlev-Haleem collection at the National Museum of Health and Medicine and the Welker collection at the University of Wisconsin-Madison.

\section{RESULTS}

\section{Volumetric Measurements}

The measured whole brain volume of the specimen from MRI scans was $506.39 \mathrm{cc}$. When converted to weight by multiplication with the value of the specific gravity of water, the estimate of whole brain weight from the MR images was $524.62 \mathrm{~g}$. A previously published value for average whole brain volume in adult harbor porpoise was $500 \mathrm{cc}$ (Marino, 1998). Also, previous work shows that the harbor porpoise brain matures very quickly, reaching $93 \%$ of adult size by weaning and full adult size by sexual maturity (Marino, 1999). Therefore, the estimated brain weight for the present specimen is not inconsistent with estimates placing its age between weaning and sexual maturity. This estimate also matches predictions of brain allometric growth in McLellan et al. (2002).

\section{Anatomical Description}

Figures 1a-I, 2a-I, and 3a-I display a sequence of originally acquired coronal MR brain sections, reconstructed horizontal sections, and reconstructed sagittal sections, respectively. Each figure also displays a labeled schematic illustration of each section, computer-generated images showing the level at 
which the section was taken in three orthogonal planes, and a computer-generated 3D reconstruction of the whole brain showing the brain digitally "cut" at the level of the section.

The figures reveal the excellent level of preservation of the spatial relationships among the brain's structures in the originally acquired magnetic resonance images and also in the digitally reconstructed images. These images show that the harbor porpoise brain possesses the same constellation of morphological features noted in the brains of other odontocete species (bottlenose dolphin, Marino et al., 2001a; beluga whale, Marino et al., 2001b; common dolphin, Morgane et al., 1980; Marino et al., 2002) and confirms findings in previous studies of the harbor porpoise brain not based on MR images (Morgane et al., 1980; Buhl and Oelschlager, 1988). For instance, the characteristic mesencephalic and pontine flexures of the brain chassis are evident in Figure $3 \mathrm{~b}-\mathrm{d}$. These flexures are a distinctive feature of cetacean brains and are reminiscent of brainstem flexure patterns in the embryonic phase of most terrestrial mammals (Nolte, 1993). In cetaceans these flexures are evident prenatally (Buhl and Oelschlager, 1988) and remain present in the adult. The presence of these flexure patterns in adults may represent a pedomorphic feature.

As in other cetaceans, the harbor porpoise cortex appears highly convoluted and expanded, particularly in the temporal region (Figs. 1g-i, 2f,g). At this gross morphological level the sulcation patterns are similar to those of other odontocetes. However, at a subtler level interspecific differences would be expected. The harbor porpoise brain also exhibits the uniquely cetacean three-tiered arrangement of limbic, paralimbic, and supralimbic arcuate cortical lobules divided by the deep limbic and paralimbic clefts (Fig. 3e). This arrangement is neuroanatomical evidence of a highly divergent evolutionary history from other mammals.

In addition to the gross morphological and cortical surface features that set the cetacean brain apart from other noncetacean mammal brains, there are differences in the spatial arrangement of several systems and structures between cetacean and noncetacean brains. For instance, whereas the cerebral peduncle lies on the ventral surface of the midbrain in most mammals, the cerebral peduncle is located high on the lateral surface of the ventral midbrain in odontocete brains (Marino et al., 2002). This is evident in the present specimen (Fig. 1g).

The proportions of various subcortical structures in the harbor porpoise brain resemble the pattern in other odontocetes as well (Morgane et al., 1980; Marino et al., 2001a, b, 2002). The cerebellum is large relative to the hemispheres. This is most evident in the coronal plane in Figure $1 \mathrm{c}-\mathrm{e}$, in the horizontal plane in Figure $2 \mathrm{~d}, \mathrm{e}$, and in the sagittal sections in Figure 3a-f. Olfactory structures are absent (but Buhl and Oelschlager, 1988, report olfactory bulbs in fetal stages in this species). Enlarged auditory processing areas, such as the inferior colliculus, are prominent in Figures 1e, 2f, and 3b,c. Also characteristic of odontocete brains is the large thalamus (Fig. 3b-e) and, in particular, the massive pulvinar, which handles visual and auditory projections. Just caudal to the thalamus is the large pons (Fig. $3 a, b)$.

As is the case in other odontocetes (Morgane et al., 1980; Marino et al., 2001a, b, 2002; Oelschlager and Oelschlager, 2001), the corpus callosum in the harbor porpoise brain is relatively thin compared with the massive hemispheres, which can be observed in Figures $1 \mathrm{~g}-\mathrm{i}, 2 \mathrm{i}$, and $3 \mathrm{a}-\mathrm{c}$. The small corpus callosum is consistent with the behavioral and electrophysiological evidence for a high degree of hemispheric independence in odontocete brains (Viamonte et al., 1968; Mukhametov et al., 1977; Mukhametov, 1984). Despite the reduced corpus callosum the adjacent cortical field, i.e., the limbic lobe and the entorhinal cortex, appear well developed in the harbor porpoise brain (Figs. 1g-i, 3c). This feature also has been noted in other odontocetes (Oelschlager and Oelschlager, 2001). 
Basal ganglia structures such as the caudate, putamen, pallidum, and internal capsule are easily visualized in Figures $1 \mathrm{i}-\mathrm{k}, 2 \mathrm{e}-\mathrm{g}, 3 \mathrm{~b}-\mathrm{e}$. However, limbic structures such as the hippocampus are diminutive in odontocete brains (Morgane et al., 1980) and the harbor porpoise is no exception. The amygdala (Figs. 1g,h, 2d,e, 3e,f) is not as reduced as one would expect given the small paleocortex.

There are some gross morphological differences between the harbor porpoise brain and the brains of other odontocetes examined. Morgane et al. (1980) noted that the separation, or diastasis, between the occipital lobes is wider in the harbor porpoise brain than in all of the other odontocete brains they examined, including the bottlenose dolphin and the beluga whale. This feature is most evident in the present specimen in Figure 2i-k. Also, whereas many odontocete brains, such as those of the bottlenose dolphin and the common dolphin, are highly elaborated, i.e., show a proliferation of tissue, along the temporal and parietal axes (Morgane et al., 1980) the harbor porpoise brain appears less elaborated in the dorsal-caudal areas than these other species. Thus, a smaller parietal and occipital cortex may be the reason why there appears to be a wider separation of the occipital lobes and an overall more flattened appearance in the harbor porpoise brain in contrast with other odontocete brains such as the bottlenose dolphin.

\section{DISCUSSION}

This article presents the first series of MRI-based anatomically labeled sectioned images of the brain of the harbor porpoise. Like our previous MRI-based studies of the brains of the adult bottlenose dolphin (Marino et al., 2001a), adult beluga whale (Marino et al., 2001b), fetal common dolphin (Marino et al., 2001c), and adult common dolphin (Marino et al., 2002) the present study displays the usefulness of imaging-based analyses of postmortem brain tissue in cetaceans. In the present study these images allow for the visualizing of the distinctive features of the harbor porpoise brain from various orientations by preserving the gross morphological and internal structure of the specimen. Such analyses are critical for building a normative database of neuroanatomical images for large-brained species such as cetaceans.

\section{ACKNOWLEDGMENTS}

We thank Dr. Hui Mao for assistance and advice during the MRI scanning. We thank Joanne Whallon for use of the Voxel View programs and Silicon Graphics, Inc. workstations at the Laser Scanning Microscopy Laboratory at Michigan State University. We also thank W. Welker, I. Siggelkow, A. Noe, and A.J. Fobbs for use of stained sections in the Wisconsin and Yakovlev-Haleem Collections, and Patsy Bryan for excellent illustrations. Finally, we thank Laurel Brothers and Saima Arshad for measurements of whole brain volume from the MRI scans. This is contribution \#143 from the Sea Research Foundation.

\section{LITERATURE CITED}

Buhl EH, Oelschlager HA. 1988. Morphogenesis of the brain in the harbour porpoise. J Comp Neurol 277:109-125.

Gaskin DE, Smith GJD, Watson AP, Yasui WY, Yurick DB. 1984. Reproduction in the porpoises (Phocoenidae): implications for management. Report of the Inter Whaling Commission, Special Issue 6:135-148.

Gingerich PD, ul Haq M, Zalmout IS, Khan IH, M Sadiq M. 2001. Origin of whales from early artiodactyls: hands and feet of Eocene Protocetidae from Pakistan. Science 293:2239-2242.

Glezer II, Jacobs M, Morgane P. 1988. Implications of the 'initial brain' concept for brain evolution in Cetacea. Behav Brain Sci 11:75-116. 
Hof PR, Glezer II, Revishchin AV, Bouras C, Charnay Y, Morgane PJ. 1995. Distribution of dopaminergic fibers and neurons in visual and auditory cortices of the harbor porpoise and pilot whale. Brain Res Bull 36:275-284.

Manger P, Sum M, Szymanski M, Ridgway S, Krubitzer L. 1998. Modular subdivisions of dolphin insular cortex: does evolutionary history repeat itself? J Cogn Neurol 10:153-166.

Marino L. 1998. A comparison of encephalization levels between adult anthropoid primates and odontocetes (toothed whales). Brain Behav Evol 51:230-238.

Marino L. 1999. Brain growth in the harbor porpoise (Phocoena phocoena) and Pacific white-sided dolphin (Lagenorhynchus obliquidens). J Mammal 80:1353-1360.

Marino L, Sudheimer K, Murphy TL, Davis KK, Pabst DA, McLellan WA, Rilling JK, Johnson JI. 2001a. Anatomy and three-dimensional reconstructions of the bottlenose dolphin (Tursiops truncatus) brain from Magnetic Resonance Images. Anat Rec 264:397-414.

Marino L, Murphy TL, DeWeerd AL, Morris JA, Fobbs AJ, Humblot N, Ridgway SH, Johnson Jl. 2001b. Anatomy and three-dimensional reconstructions of the brain of the white whale (Delphinapterus leucas) from magnetic resonance images. Anat Rec 262:429-439.

Marino L, Murphy TL, Gozal L, Johnson Jl. 2001c. Magnetic resonance imaging and three-dimensional reconstructions of the brain of a fetal common dolphin, Delphinus delphis. Anat Embryol 203:393-402.

Marino L, Sudheimer K, Pabst DA, McLellan WA, Filsoof, D, Johnson JI. 2002. Neuroanatomy of the common dolphin (Delphinus delphis) as revealed by magnetic resonance images (MRI). Anat Rec 268:411-429

McLellan WA, Koopman HN, Rommel SA, Read AJ, Potter CW, Nicolas JR, Westgate AJ, Pabst DA. 2002. Ontogenetic allometry and body composition of harbour porpoises (Phocoena phocoena L.) from the western North Atlantic. J Zool Lond 257:457-471.

Morgane PJ, Jacobs MS, MacFarland WL. 1980. The anatomy of the brain of the bottlenose dolphin (Tursiops truncatus). Surface configurations of the telencephalon of the bottlenose dolphin with comparative anatomical observations in four other cetacean species. Brain Res Bull 5(Suppl 3):1-107.

Mukhametov LM. 1984. Sleep in marine mammals. Exp Brain Res 8:227-238.

Mukhametov LM, Supin AY, Polyakova IG. 1977. Interhemispheric asymmetry of the electroencephalographic sleep patterns in dolphins. Brain Res 134:581-584.

Nolte J. 1993. The human brain. St. Louis: Mosby Year Book.

Oelschlager HA, Buhl, EH. 1985. Occurrence of an olfactory bulb in the early development of the harbor porpoise (Phocoena phocoena L.). In: Duncker HR, Fleischer G, editors. Functional morphology in vertebrates. New York: Fischer. p 695-698.

Oelschlager HA, Oelschlager JS. 2001. Brain. In: Perrin WF, Wursig B, Thewissen JGM, editors. Encyclopedia of marine mammals. San Diego: Academic Press. p 133-158. 
Palka DL, Read AJ, Westgate AJ, Johnston DW. 1996. Summary of current knowledge of harbour porpoises in US and Canadian Atlantic waters. Rep Int Whal Comm 46:559-565.

Popov VV, Ladygina TF, Supin AYa. 1986. Evoked potentials of the auditory cortex of the porpoise, Phocoena phocoena. J Comp Phys 158:705-511.

Read AJ. 1990. Age at sexual maturity and pregnancy rates of harbour porpoises Phocoena phocoena from the Bay of Fundy. Can J Fish Aquat Sci 47:561-565.

Read AJ, Hohn A. 1995. Life in the fast lane: the life history of harbor porpoises from the Gulf of Maine. Mar Mamm Sci 11:423-440.

Read AJ, Tolley KA. 1997. Postnatal growth and allometry of harbor porpoises from the Bay of Fundy. Can J Zool 75:122-130.

Read AJ, Westgate AJ. 1997. Monitoring the movement patterns of harbour porpoises (Phocoena phocoena) from the Bay of Fundy. Mar Biol 130:315-322.

Recchia CR, Read AJ. 1989. Stomach contents of harbor porpoises, Phocoena phocoena (L.), from the Bay of Fundy. Can J Zool 67:2140-2146.

Revishchin AV, Garey LJ. 1990. The thalamic projection to the sensory neocortex of the porpoise, Phocoena phocoena. J Anat 169:85-102.

Revishchin AV, Garey LJ. 1993. Neuronal morphology in the lateral geniculate nucleus of the porpoise (Phocoena phocoena). J Hirnforsch 34:25-34.

Ridgway SH. 1986. The central nervous system of the bottlenose dolphin. In: Schusterman RJ, Thomas JA, Wood FG, editors. Dolphin cognition and behavior: a comparative approach. Hillsdale, NJ: Lawrence Erlbaum. p 31-60.

Sokolov VE, Ladygina TF, Supin AYa. 1972. Localization of sensory zones in the dolphin's cerebral cortex. Proc Acad Sci USSR 202:490-493.

Sorensen TB, Kinze CC 1994. Reproduction and reproductive seasonality in Danish harbour porpoises, Phocoena phocoena. Ophelia 38:159-176.

Stephan H, Frahm H, Baron G. 1981. New and revised data on volumes of brain structures in insectivores and primates. Folia Primatol 25:1-29.

Stuart LJ, Morejohn GV. 1980. Developmental patterns in osteology and external morphology in Phocoena phocoena. Report of the International Whaling Commission, Special Issue 3:133-142.

Supin AYa, Mukhametov LM, Ladygina TF, Popov VV, Mass AM, Polvakova IG. 1978. Electrophysiological study of the dolphin brain. Moscow: Nauka Press. p 29-85.

Thewissen JGM, Williams EM, Roe LJ, Hussain ST. 2001. Skeletons of terrestrial cetaceans and the relationship of whales to artiodactyls. Nature 413:277-281.

Viamonte M, Morgane PJ, Galliano RE, Nagel EL, McFarland WL. 1968. Angiography in the living dolphin and observations on blood supply to the brain. Am J Physiol 214:1225-1249. 
Walton MJ. 1997. Population structure of harbour porpoises Phocoena phocoena in the seas around the UK and adjacent waters. Proc R Soc Lond B Biol Sci 264:89-94. 